InterSedes, Revista electrónica de las sedes regionales de la Universidad de Costa Rica,

ISSN 2215-2458, Vol XXI, Número 43, Enero - Julio, 2020.

10.15517/isucr.v21i43.41991 | intersedes.ucr.ac.cr | intersedes@ucr.ac.cr

\title{
CARTOGRAFÍA DEL PERFIL SOCIOECONÓMICO Y DE VIVIENDA EN LA MICROCUENCA RÍO BURÍO QUEBRADA SECA (COSTA RICA)
}

\section{CARTOGRAPHY OF THE SOCIOECONOMIC AND HOUSING PROFILE IN THE MICRO-BASIN OF THE RÍO BURÍO QUEBRADA SECA (COSTA RICA)}

\author{
Ramón Masís-Campos ${ }^{1}$ \\ Isabel Avendaño-Flores ${ }^{2}$ \\ Jonnathan Reyes-Chaves ${ }^{3}$
}

\begin{tabular}{|l|l}
\hline Recibido: 04.05 .19 & Aprobado: 30.04 .20
\end{tabular}

DOI: $10.15517 /$ isucr.v21i43.41991

\section{Resumen}

El objetivo principal de la investigación es cartografiar el perfil socioeconómico y de vivienda en la microcuenca río Burío-quebrada Seca con el fin de favorecer la implementación de acciones de restauración, conservación, mitigación en el sistema fluvial y el ordenamiento territorial en el área de estudio.

La metodología estuvo compuesta de tres grandes etapas que son las siguientes: descripción de los datos, preparación de los datos en el gestor de base de datos, publicación de datos con la comunidad.

En la microcuenca estudiada es ocupada es su mayoría por el cantón Belén, donde se han reportado importantes avenidas durante las últimas tres décadas $(1981,2004,2007,2008)$ que han afectado significativamente la población residente, principalmente con daños en viviendas y puentes. Paralelamente, desde el 2005, la Sala Constitucional emitió el voto $\mathrm{N}^{\mathrm{o}} 4050$, en el cual ordenó la conformación de una Comisión Interinstitucional.

En términos de densidad poblacional la microcuenca para 2011 tenía en promedio 4160 habitantes $/ \mathrm{km}^{2}$. Hay un predominio de residencias urbanas en la microcuenca, el 97,5\% de las viviendas que se encuentra en esta zona. Casi un $87 \%$ de las viviendas del área de estudio corresponde con casas independientes. Según el censo 2011, para el área de estudio aproximadamente 190 viviendas no cuentan con alcantarillado sanitario o tanque séptico, distribuidas en 82 UGM(Unidad Geoestadística Mínima). Es decir, las aguas negras y residuales son dispuestas directamente a ríos, quebradas, zanjas o huecos.

\footnotetext{
${ }^{1}$ Docente. Universidad de Costa Rica, San Pedro, San José, Costa Rica. Email: ramon.masiscampos@ucr.ac.cr

${ }^{2}$ Docente. Universidad de Costa Rica, San Pedro, San José, Costa Rica. Email: isabel.avendano@ucr.ac.cr

${ }^{3}$ Docente. Universidad de Costa Rica, San Pedro, San José, Costa Rica. Email: jonnathan.reyeschaves@ucr.ac.cr
} 
En la microcuenca baja presenta una cantidad considerable de eventos en el sector de San Antonio de Belén, sector que se caracteriza por presentar mayores áreas en la categoría de alta amenaza por inundación.

Palabras Claves: Cartografía; Socieconómico; vivienda; río Burío; quebrada seca; microcuenca.

\begin{abstract}
The main objective of the research is to map the socioeconomic and housing profile in the BuríoQuebrada Seca micro-basin in order to favor the implementation of restoration, conservation, mitigation actions in the fluvial system and territorial ordering in the study area. The methodology was composed of three main stages: description of data, preparation of data in the database manager, and publication of data with the community.

The studied micro-basin, is mostly occupied by the Belén canton, where important avenues have been reported during the last three decades (1981, 2004, 2007, 2008) that have significantly affected the resident population, mainly with damage to dwellings and bridges. In parallel, since 2005, the Constitutional Chamber issued the vote No. 4050, in which it ordered the formation of an Inter-Institutional Commission. In terms of population density, the micro-basin for 2011 had an average of 4160 inhabitants per $\mathrm{km}^{2}$. There is a predominance of urban residences in the micro watershed, $97.5 \%$ of the dwellings are in this area. Almost $87 \%$ of the homes in the study area correspond to independent houses.

According to the 2011 census, for the study area, approximately 190 households do not have sanitary sewage or septic tank, distributed in 82 UGM. That is, the black and residual waters are disposed directly to rivers, ravines, trenches or hollows.

In the low micro-basin it presents a considerable amount of events in the sector San Antonio of Belén, sector that is characterized to present greater areas in the category of high threat by flood.
\end{abstract}

Keywords: Cartography; Socioeconomic; housing; río Burío; quebrada seca; micro-basin.

\title{
Agradecimientos:
}

Los investigadores desean manifestar su reconocimiento a las Vicerrectorías de Investigación y Acción Social y a la Escuela de Geografía de la Universidad de Costa Rica, por su apoyo en la inscripción y desarrollo del proyecto denominado "Cartografía del perfil socieconómico y de vivienda en la microcuenca del río Burío quebrada Seca "inscrito con los códigos 217-B6-099 y ED-3236. También queremos agradecer a la Municipalidad de Heredia por su apoyo financiero y a las Asociaciones de Desarrollo por el tiempo brindado.

\section{Introducción}

El área de la microcuenca comprende un territorio cercano a los $22 \mathrm{~km}^{2}$ y es drenada por el río Burío, la quebrada Seca y la quebrada Aries que recorren aproximadamente $19 \mathrm{~km}$ desde la naciente cercana a Getsamaní hasta la bifurcación con el río Bermúdez. En este espacio geográfico se ha modificado el uso de la tierra y la dinámica del sistema fluvial, provocando altos 
picos de descarga hídrica principalmente en su parte baja (barrio Cristo Rey, La Asunción, San Antonio, San Rafael) afectando en forma directa y reiterada a la población por décadas

Cuando el ser humano ha ocupado estas áreas para desarrollar sus actividades socioeconómicas y se presentan desbordamientos, impactan como pérdidas económicas, sociales o ambientales, especialmente en espacios densamente poblados.

Ante tales consecuencias, la Municipalidad de Belén ha invertido en los últimos años en trabajos de dragado, diques, muros de gaviones, expropiaciones de tierras y estudios de factibilidad para el transvase de aguas. No obstante, todavía se carece de un diagnóstico a nivel de análisis de la microcuenca, para así consolidar las políticas de ordenamiento y manejo del riesgo en estos espacios.

Un caso representativo en la Gran Área Metropolitana (GAM) de lo anteriormente expuesto, lo constituye la microcuenca del río Burío. Esta área de drenaje se localiza en las provincias Heredia y Alajuela, específicamente los cantones: San Rafael, Barva, Heredia, Flores, Belén y Alajuela. Además el sistema fluvial es afluente de la subcuenca del río Virilla. Su localización está centrada en las coordenadas: $10^{\circ} \mathrm{N}$ y $84^{\circ} 9^{\prime} \mathrm{O}$ (figura 1 ).

Figura 1. Localización

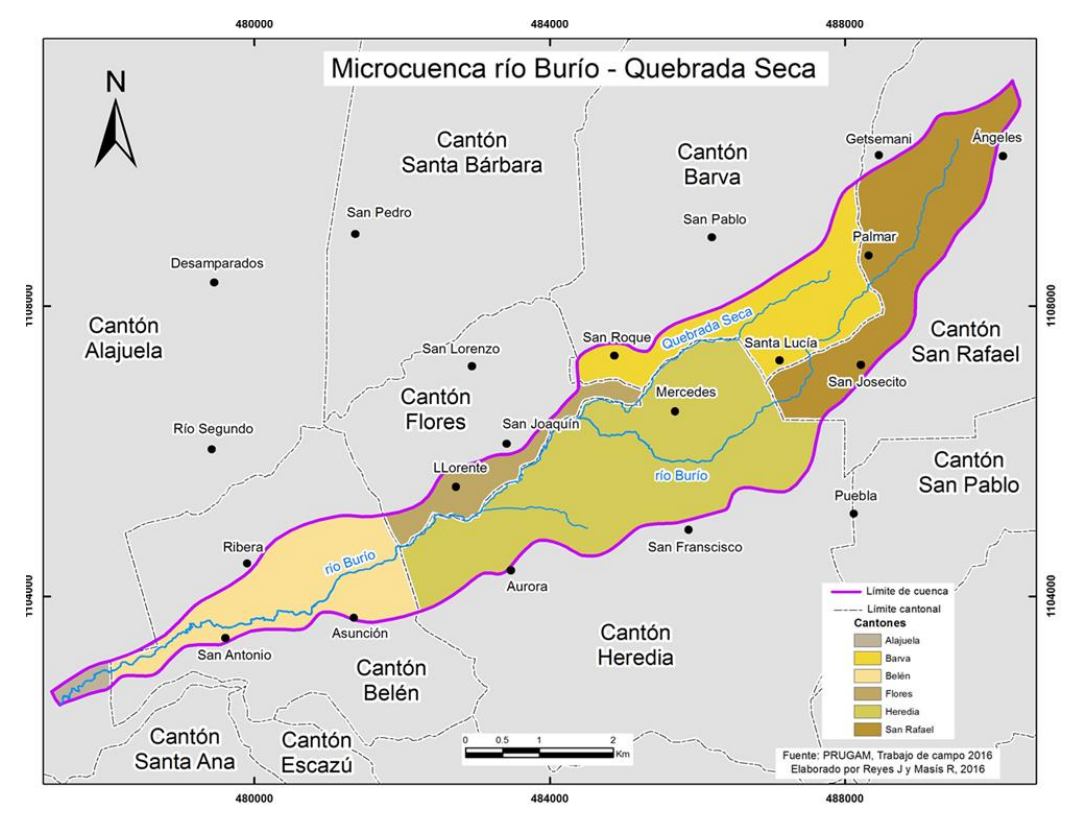

Fuente: PRUGAM y trabajo de campo 


\section{Metodología}

Descripción de los datos

Para abordar el análisis del perfil socioeconómico de la microcuenca del río Burío se utilizó la base de datos del X Censo Nacional de Población y VI Censo Nacional de Vivienda 2011 del Instituto de Estadística y Censo (INEC) y las Unidades Geoestadísticas Mínimas (UGM). La UGM es una división territorial mínima creada para fines estadísticos del Censo 2011 y corresponde con elementos de la realidad con tamaño definido por calles y cuadras. Este sistema de trabajo se ha probado con éxito en países del área de América Latina.

Respecto al área de estudio se analizó 814 UGM que comprenden y atraviesan la microcuenca, distribuidas de la siguiente manera: Heredia (468), Barva (99), San Rafael (96), Belén (75), Flores (67), San Rafael de Alajuela (9). La extensión promedio de las UGM es de 3.5 ha, mientras que el valor mínimo y máximo fue de 0.06 ha y 142.94 ha respectivamente (figura 2).

\section{Figura 2. Cantidad y distribución de UGM por cantón en el área de estudio}

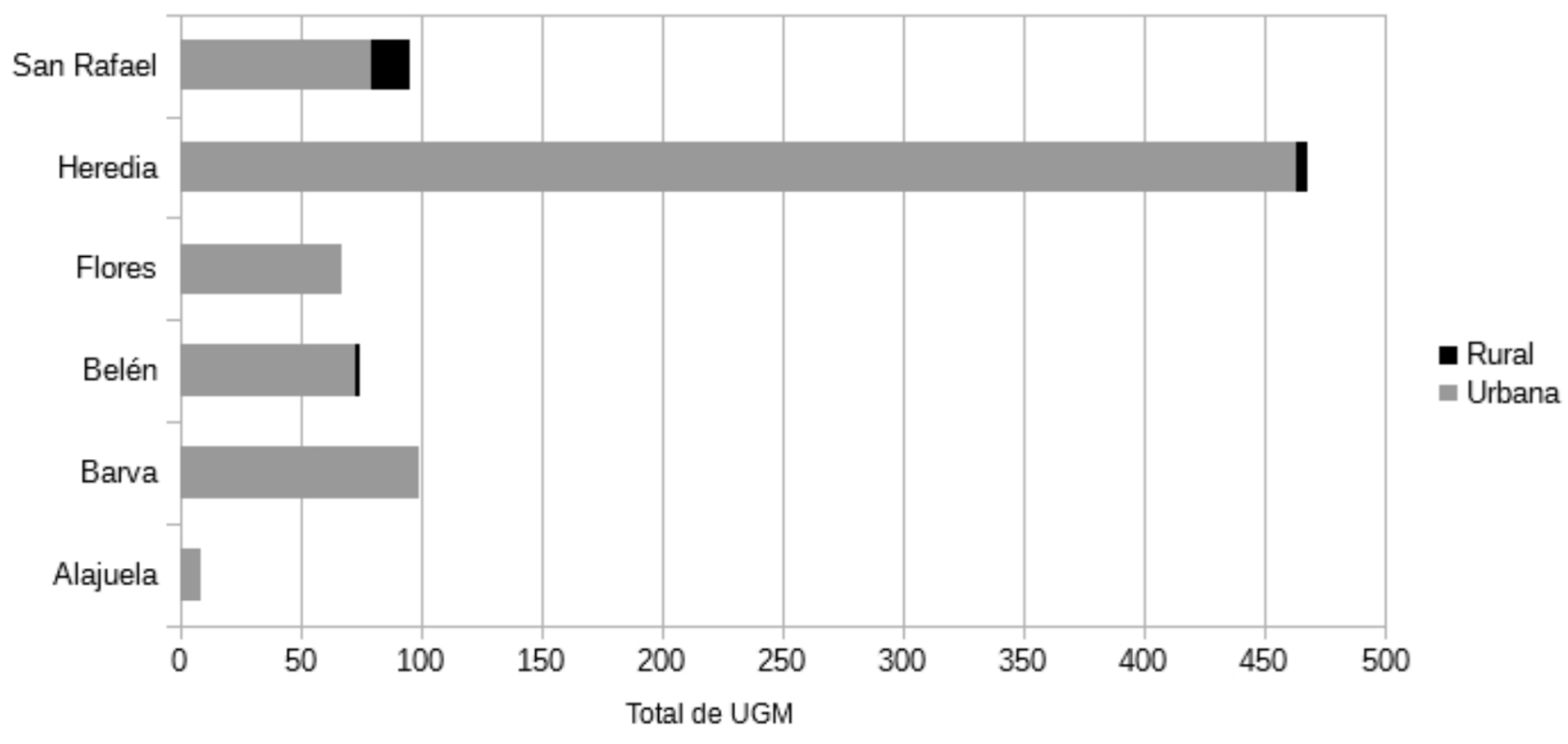

Fuente: INEC, 2011.

Asimismo, se cuenta con una cartografía base del país (división política-administrativa, hidrográfica) georeferenciada en la proyección Transversal de Mercator para Costa Rica 
(CRTM05), escala 1:5000. Para este fin, se usará capas vectoriales de distritos, cantones, provincias, curvas de nivel y ríos del Sistema Nacional de Información Territorial (SNIT). Además, se cuenta con datos de apoyo de OpenStreetMap (OSM) y la cartografía derivada del Plan Regional Urbano del Gran Área Metropolitana de Costa Rica (PRUGAM). Todos los datos geográficos, se describen en detalle en la tabla 1.

Tabla 1. Fuente de datos geoespaciales del proyecto

\begin{tabular}{|c|c|c|}
\hline Área de estudio & Temática & Fuente de datos \\
\hline \multirow{4}{*}{$\begin{array}{l}\text { Microcuenca del } \\
\text { río Burío- } \\
\text { quebrada Seca }\end{array}$} & $\begin{array}{l}\text { X Censo Nacional } \\
\text { de Población y VI } \\
\text { Censo Nacional de } \\
\text { Vivienda } 2011\end{array}$ & $\begin{array}{l}\text { INEC. X Censo Nacional de Población y VI Censo } \\
\text { Nacional de Vivienda } 2011 \text {. Base de datos cedida } \\
\text { para el proyecto ED3226 }\end{array}$ \\
\hline & Cartografía Base & $\begin{array}{l}\text { SNIT. Distritos, cantones, provincias, curvas de } \\
\text { nivel y ríos a partir del WFS(Web Feature } \\
\text { Service).Disponible en } \\
\text { http://www.snitcr.org/servicios/datos/wfs? }\end{array}$ \\
\hline & $\begin{array}{l}\text { Cartografía } \\
\text { PRUGAM }\end{array}$ & $\begin{array}{l}\text { PRUGAM. La cartografía de usos de la tierra a } \\
\text { escala 1:10.000 para la Gran Área Metropolitana, } \\
\text { en el marco del proyecto PRUGAM } \\
\text { http://www.mivah.go.cr/PRUGAM.shtml }\end{array}$ \\
\hline & $\begin{array}{l}\text { Cartografía de } \\
\text { OSM }\end{array}$ & $\begin{array}{l}\text { Base de datos del área de estudio. Disponible en } \\
\text { https://www.openstreetmap.org }\end{array}$ \\
\hline
\end{tabular}

Fuente: Elaboración propia.

Preparación de los datos en el gestor de base de datos

Se migró el censo que originalmente fue desarrollada en el programa SPSS( Statistical Package for the Social Sciences ) al sistema gestor de base de datos Postgresql con la extensión geográfica PostGis para ejecutar las operaciones de: almacenar, consulta, manipular y relacionar los objetos 
espaciales con datos literales del censo de población y vivienda, para ser consumidos mediante tablas y vistas en sistemas de información geográfica de escritorio como: QGIS y ArcGis.

Por ejemplo, se realizaron operaciones espaciales con lenguaje SQL (Structured Query Language) y la función st_intersects para ejecutar la consulta para ubicar las Unidades Geoestadísticas Mínimas dentro de la microcuenca por distrito, cantón y provincia.

Figura 3. Consulta espacial SQL de UGMS por división política en el área de estudio 1.SELECT DISTINCT u.ugm_llave AS ugm, // Selecciona los atributos

2.u.nomb_ugec AS canton,

3.u.nomb_uged AS distrito

4.FROM xcenso_2011 c,

5.ugm u,

6. microcuenca $\mathrm{m}$

7.WHERE c.id_ugm::double precision = u.ugm_llave AND st_intersects(m.geom, u.geom) Implementa la función 180oblació

8. GROUP BY c.id_ugm, u.ugm_llave, u.nomb_ugec, u.nomb_uged, u.geom

9. ORDER BY u.nomb_ugec,u.nomb_uged // Ordena los resultado

\begin{tabular}{|r|r|l|l|}
\hline & $\begin{array}{l}\text { ugm } \\
\text { double precision }\end{array}$ & $\begin{array}{l}\text { canton } \\
\text { character varying(40) }\end{array}$ & $\begin{array}{l}\text { distrito } \\
\text { character varying(50) }\end{array}$ \\
\hline $\mathbf{1}$ & 983 & ALAJUELA & SAN RAFAEL \\
\hline $\mathbf{2}$ & 11351 & ALAJUELA & SAN RAFAEL \\
\hline $\mathbf{3}$ & 11838 & ALAJUELA & SAN RAFAEL \\
\hline $\mathbf{4}$ & 16373 & ALAJUELA & SAN RAFAEL \\
\hline $\mathbf{5}$ & 18299 & ALAJUELA & SAN RAFAEL \\
\hline $\mathbf{6}$ & 23380 & ALAJUELA & SAN RAFAEL \\
\hline $\mathbf{7}$ & 32605 & ALAJUELA & SAN RAFAEL \\
\hline $\mathbf{8}$ & 49266 & ALAJUELA & SAN RAFAEL \\
\hline $\mathbf{9}$ & 30.548 & AT.ATTTFT.A & SAN RAFAFT. \\
\hline
\end{tabular}

Fuente: INEC, 2011

Además, se desarrollaron vistas personalizadas, tal es el caso para calcular la cantidad y densidad poblacional por Unidad Geoestadística mínima dentro del área de estudio (figura 4). 
Figura 4. Vista SQL para estimar densidad poblacional por UGM en el área de estudio 1.SELECT DISTINCT u.ugm_llave AS ugm, // Selecciona los atributos

2. u.nomb_ugec AS canton,

3. u.nomb_uged AS distrito,

4. $\quad$ count(c.h05c_total) AS total_poblacion,

5. u.area_m2 / 1000000::numeric AS area,

6. (count(c.h05c_total)::numeric / (u.area_m2 / 1000000::numeric))::integer AS 7. Densidad,

8. u.geom

9. FROM xcenso_2011 c,

10. $\operatorname{ugm} \mathrm{u}$,

11. microcuenca $\mathrm{m}$

12. WHERE c.id_ugm::double precision $=$ u.ugm_llave AND c.h05a_total IS NOT NULL 13.

AND c.h05b_total IS NOT NULL AND c.h05c_total IS NOT NULL AND 14. 14.st_intersects(m.geom, u.geom) AND c.id_hogar $<>0$

15. GROUP BY c.id_ugm, u.ugm_llave, u.nomb_ugec, u.nomb_uged, u.geom, u.area_m2

16. ORDER BY u.ugm_llave;

\begin{tabular}{|c|c|c|c|c|c|c|c|}
\hline & $\begin{array}{l}\text { ugm } \\
\text { double precision }\end{array}$ & $\begin{array}{l}\text { canton } \\
\text { character varying(40) }\end{array}$ & $\begin{array}{l}\text { distrito } \\
\text { character varying(50) }\end{array}$ & $\begin{array}{l}\text { total_poblacion } \\
\text { bigint }\end{array}$ & $\begin{array}{l}\text { area } \\
\text { numeric }\end{array}$ & $\begin{array}{l}\text { densidad } \\
\text { integer }\end{array}$ & $\begin{array}{l}\text { geom } \\
\text { geometry(MultiPolygon,5367) }\end{array}$ \\
\hline 1 & 66 & FLORES & SAN JOAQUIN & 27 & 0.00439017698604000000 & 6150 & $0106000020 F 7140000010000$ \\
\hline 2 & 79 & HEREDIA & MERCEDES & 10 & 0.01395311509590000000 & 717 & $0106000020 \mathrm{~F} 7140000010000$ \\
\hline 3 & 82 & SAN RAFAEL & ANGELES & 347 & 0.52750130060000000000 & 658 & $0106000020 F 7140000010000$ \\
\hline 4 & 162 & HEREDIA & HEREDIA & 125 & 0.00635986007173000000 & 19655 & $50106000020 F 7140000010000$ \\
\hline 5 & 414 & SAN RAFAEL & SAN JOSECITO & 86 & 0.02287260100150000000 & 3760 & $0106000020 F 7140000010000$ \\
\hline 6 & 424 & BARVA & SÄNTẢ LUCIÄ & 271 & 0.03162364106000000000 & 8570 & $0106000020 \mathrm{~F} 7140000010000$ \\
\hline 7 & 538 & HEREDIA & SAN FRANCISCO & 190 & 0.00443347487039000000 & 42856 & $0106000020 \mathrm{~F} 7140000010000$ \\
\hline 8 & 542 & HEREDIA & MERCEDES & 53 & 0.00495028559695000000 & 10706 & $0106000020 \mathrm{~F} 7140000010000$ \\
\hline 9 & 578 & HEREDIA & MERCEDES & 110 & 0.01028878565220000000 & 10691 & $0106000020 F 7140000010000$ \\
\hline 10 & 583 & FLORES & LLORENTE & 520 & 0.07643431736750000000 & 6803 & $0106000020 \mathrm{~F} 7140000010000$ \\
\hline
\end{tabular}

Fuente: INEC, 2011

Publicación de datos con la comunidad

Para efectos de interactuar los resultados del Censo 2011 y la realidad de los habitantes y actores sociales respecto a percepciones o problemáticas socioeconómicas y ambientales de la microcuenca del río Burío, se recurrió a diseñar una herramienta de colección de datos por medio de un sondeo en la web. 
Para implementar el sondeo se recurrió a ArcGis Online. Esta es una plataforma propietaria colaborativa con base en la nube para crear y compartir mapas, aplicaciones, datos y contenido geográfico. Además, permite la interacción con los datos organizacionales compartiendo el contenido relacionado a una actividad común.

Otras ventajas de usar esta plataforma es su alcance mundial por medio de la internet a través de dispositivos como teléfonos inteligentes, tabletas o computadoras, por lo que son numerosos y diversos los tipos de usuarios interesados en ver y editar mapas web. Adicionalmente, no representa ningún tipo de entrenamiento o conocimiento para los usuarios finales para navegar, consultar o descargar datos geográficos.

Se utilizó la base de datos de la Dirección Nacional de Desarrollo de la Comunidad (DINADECO) y las municipalidades para identificar actores sociales como son las Asociaciones de Desarrollo Integral (ADIS). Para el área de estudio existen más de 45 ADI activas o pasivas. Distribuidas de la siguiente manera(tabla 2 y 3 ):

Tabla 2. Cantidad de ADIS activas por cantón en la microcuenca del río Burío-quebrada Seca

\begin{tabular}{|c|c|}
\hline Cantón & Cantidad \\
\hline Barva & 5 \\
\hline Belén & 5 \\
\hline Flores & 7 \\
Heredia & 17 \\
\hline San Rafael & 10 \\
\hline Alajuela (San Rafael) & 1 \\
\hline Total & $\mathbf{4 5}$ \\
\hline
\end{tabular}

Fuente: DINADECO, 2015 
Tabla 3. Distribución de ADIS activas en la microcuenca del río Burío-quebrada Seca

\begin{tabular}{|c|c|c|}
\hline Cantón & Distrito & Nombre de la organización comunitaria \\
\hline \multirow[t]{4}{*}{ Barva } & Barva & $\begin{array}{l}\text {-Unión Cantonal de Asociaciones de desarrollo de Barva, Heredia } \\
\text {-Asociacion de Desarrollo Especifica Pro Cen Cinai y Bienestar Comunal de } \\
\text { Barva,Heredia } \\
\text {-ADI de Barva de Heredia }\end{array}$ \\
\hline & San Roque & ADI de San Roque de Barva de Heredia \\
\hline & Santa Lucía & ADI de Santa Lucía de Barva de Heredia \\
\hline & Total & 5 \\
\hline \multirow{4}{*}{ Belén } & Ribera & $\begin{array}{l}\text {-Asociación de Desarrollo Especifica Pro Cen Cinai Y Bienestar Comunal de } \\
\text { Ribera de Belen, Heredia } \\
\text {-ADI de La Ribera de Belén Heredia }\end{array}$ \\
\hline & Asunción & -ADI de La Asunción de Belén de Heredia \\
\hline & San Antonio & $\begin{array}{l}\text {-Asociación de Desarrollo Especifica Pro Vivienda y Damnificados del Río } \\
\text { quebrada Seca de San Antonio de Belén } \\
\text {-Asociación De Desarrollo Especifica Pro Cen Cinai y Bienestar Comunal de } \\
\text { San Antonio de Belén, Heredia }\end{array}$ \\
\hline & Total & 5 \\
\hline \multirow[b]{2}{*}{ Flores } & Llorente & $\begin{array}{l}\text { - ADI de Barrio Cristo Rey de Flores de Heredia } \\
\text { - ADI de Barrio Santa Elena de Flores de Heredia } \\
\text { - ADI de Llorente de Flores de Heredia }\end{array}$ \\
\hline & San Joaquín & $\begin{array}{l}\text {-Asociación de Desarrollo Especifica Pro Cen Cinai y Bienestar Comunal de } \\
\text { San Joaquín de Flores, Heredia } \\
\text {-ADI de Barrio Santísima Trinidad, Flores } \\
\text { - ADI de San Joaquin de Flores de Heredia } \\
\text {-Unión Cantonal de Asociaciones de Flores Heredia } \\
7\end{array}$ \\
\hline
\end{tabular}




\begin{tabular}{|c|c|c|}
\hline \multirow[t]{4}{*}{ Heredia } & $\begin{array}{l}\text { San } \\
\text { Francisco }\end{array}$ & $\begin{array}{l}\text {-Asociación de Desarrollo Específica Pro Mejoras de Nisperos Tres San } \\
\text { Francisco, Heredia } \\
\text {-Asociación de Desarrollo Especifica Para Administración de Áreas } \\
\text { Comunales En La Urb.Aries } \\
\text {-Asociación de Desarrollo Especifica Para La Seguridad Comunitaria Del } \\
\text { Residencial Las Palmeras Heredia } \\
\text { - ADI de San Francisco de Heredia } \\
\text {-Administra áreas Comunales De Urb. Jardines Del Oeste } \\
\text {-Asociación de Desarrollo Especifica Pro Cen Cinai y Bienestar Comunal de } \\
\text { Guarari, Heredia } \\
\text {-Asociación de Desarrollo Específicapro Seguridad Comunitaria de Los Lagos } \\
\text { de Heredia }\end{array}$ \\
\hline & Mercedes & $\begin{array}{l}\text {-Asociación de Desarrollo Especifica Pro Cen Cinai y Bienestar Comunal de } \\
\text { Mercedes Norte de Heredia } \\
\text {-Asociación De Desarrollo Específica Pro Const. Parque de Recreación de } \\
\text { Urbanización Zumbado, Heredia } \\
\text { - ADI de Mercedes Norte Y Barrio España de Heredia } \\
\text {-ADI de San Jorge de Mercedes de Heredia }\end{array}$ \\
\hline & Heredia & $\begin{array}{l}\text {-Federación de Uniones Cantonales de La Provincia/Heredia } \\
\text {-Unión Cantonal de Asociaciones de Heredia } \\
\text { - ADI de Ciudadela Cubujuqui de Heredia } \\
\text { - ADI de Barrio Corazón de Jesús de Heredia } \\
\text { - ADI de Barrio Fátima de Heredia } \\
\text { - ADI de Residencial María Auxiliadora de Heredia }\end{array}$ \\
\hline & Total & 17 \\
\hline $\begin{array}{c}\text { San } \\
\text { Rafael }\end{array}$ & San Rafael & $\begin{array}{l}\text {-Asociación de Desarrollo Especifica Pro Cen Cinai Y Bienestar Comunal de } \\
\text { Bajo Los Molinos de San Rafael } \\
\text {-Adi de Lotes Peralta de San Rafael de Heredia } \\
\text { - ADI de Montecito de San Rafael de Heredia } \\
\text { - Asociación De Desarrollo Especifica Pro Cen Cinai y Bienestar Comunal De }\end{array}$ \\
\hline
\end{tabular}




\begin{tabular}{|l|l|l|}
\hline & $\begin{array}{l}\text { Lotes Peralta } \\
- \text { Unión Cantonal De Asoc.Desarrollo de San Rafael de Heredia } \\
\text { ADI de San Rafael de Heredia }\end{array}$ \\
\hline \multirow{2}{*}{ Ángeles } & -ADI de Los Ángeles de San Rafael de Heredia \\
\hline Total & $\mathbf{1 0}$ \\
\hline
\end{tabular}

Fuente: DINADECO, 2015

Resultados

Población

El INEC ofreció para el proyecto los datos para 16 distritos (Belén, La Asunción, La Ribera, Santa Lucía, Barva, San Roque, Llorente, San Joaquín, Ulloa, San Francisco, Mercedes, Heredia, San Josecito, San Rafael, Ángeles, San Rafael de Alajuela) que atraviesa el área de estudio.

Preliminarmente los cantones de San Rafael, Barva, Heredia, Flores, Belén y el distrito de San Rafael de Alajuela tenían una población de 235254 habitantes según el censo 2011. No obstante, la delimitación natural de la microcuenca no corresponde con límites políticos-administrativos. Por lo que se tuvo que restringir a únicamente a 814 UGM que se encuentran total o parcialmente dentro del área de estudio.

Es así como, la población total de la microcuenca río Burío-quebrada Seca se estimó en 115776 personas, distribuidos en 55637 hombres (48\%) y 60139 mujeres (52\%). Contextualizando el valor estadístico, la población del área de estudio representa, aproximadamente el $25 \%$ de la población de la provincia Herediana y un 2,5\% del total de la población del país (INEC, 2011).

En la tabla 4 se observa la distribución poblacional, por distritos en las 814 UGM(Unidad Geoestadística Mínima) que constituyen el área de estudio. Heredia es el cantón más populoso con 55207 personas, es decir el 48\% de los habitantes del área de estudio. Además, en este cantón 
se encuentran los distritos más poblados: Mercedes con 25744 personas (22\%) distribuidos en 205 UGMS y San Francisco con 18324 habitantes (16\%) en 130 UGMS de la microcuenca.

Por otro lado, los restantes cantones aportan el 52\% de la población de la microcuenca. En la parte alta San Rafael y Barva concentran el 29\% de los habitantes en 195 UGMS, siendo San Josecito el distrito más poblado con 10607 personas.

El restante 23\% de la población, es decir 27137 habitantes se distribuyen en 151 UGM en los cantones de Flores, Belén y el distrito de San Rafael de Alajuela(tabla 4).

Tabla 4. Población distribuida en las 814 UGM del área de estudio

\begin{tabular}{lrr} 
& \multicolumn{1}{c}{ Total } & \multicolumn{1}{c}{ Total de UGM } \\
\hline Alajuela & $\mathbf{2 3 5 5}$ & $\mathbf{9}$ \\
\hline San Rafael & 2355 & 9 \\
\hline Barva & $\mathbf{1 4 9 6 9}$ & $\mathbf{9 9}$ \\
\hline Barva & 4166 & 35 \\
\hline San Roque & 3390 & 20 \\
\hline Santa Lucía & 7413 & 44 \\
\hline Belén & $\mathbf{1 3 0 0 5}$ & 75 \\
\hline La Asunción & 2872 & 8 \\
\hline La Ribera & 8173 & 12 \\
\hline San Antonio & 8137 & 55 \\
\hline Flores & $\mathbf{1 1 8 1 3}$ & $\mathbf{6 7}$ \\
\hline Llorente & 7413 & 40 \\
\hline San Joaquín & 3676 & 27 \\
\hline Heredia & $\mathbf{5 5 2 0 7}$ & $\mathbf{4 6 8}$ \\
\hline Heredia & 9664 & 124 \\
\hline Mercedes & 25744 & 205 \\
\hline San Francisco & 18324 & 130 \\
\hline Ulloa & 1475 & 9
\end{tabular}


InterSedes, $\mathbf{N}^{\circ}$ 43. Vol XXI (2020). ISSN 2215-2458

\begin{tabular}{lrr}
\hline San Rafael & $\mathbf{1 8 4 2 7}$ & $\mathbf{9 6}$ \\
\hline Ángeles & 5386 & 27 \\
\hline San Josecito & 10607 & 61 \\
\hline San Rafael & 2434 & 8 \\
\hline Total & $\mathbf{1 1 5 7 7 6}$ & $\mathbf{8 1 4}$ \\
\hline
\end{tabular}

Fuente: INEC, 2011.

Igualmente en términos de densidad poblacional la microcuenca para 2011 tenía en promedio 4160 habitantes $/ \mathrm{km}^{2}$. Esto se puede interpretar que los centros cantonales periféricos a Heredia (Barva, San Joaquín, San Rafael, San Antonio) están prácticamente conurbados, es decir, que existe una fusión de dos o más ciudades por efecto del crecimiento urbano, llegando a formar una sola mancha o extensión urbana.

Las UGM que representan los distritos periféricos a la ciudad de Heredia, es decir San Josecito, Mercedes y San Francisco presentan una alta densidad poblacional. En caso de San Josecito la densidad puede llegar a casi 10000 habitantes $/ \mathrm{km}^{2}$,

Mientras que en distritos como: Los Ángeles, La Rivera y Asunción tienen densidades menores de 880-1440 habitantes $/ \mathrm{km}^{2}$, en parte porque hay una menor intensificación del uso residencial. En Los Ángeles hay un predominio del paisaje rural y con viviendas dispersas sobre las carreteras, mientras que en los distritos de Belén predominan usos de la tierra dedicados a industria, zonas francas, comercio y en menor residencial.

En cuanto a la distribución por sexo y grupos etarios, existe una diferencia de 3947 más hombres que mujeres, es decir, el $52 \%$ de la población en el área de estudio corresponde al género masculino y un $48 \%$ es femenino. Es importante destacar para el resto de los distritos se sigue esa tendencia, excepto para Heredia, donde la distribución se invierte, siendo el 52\% de la población de mujeres. 
Figura 5. Pirámide poblacional de la microcuenca del río Burío - quebrada Seca, 2011

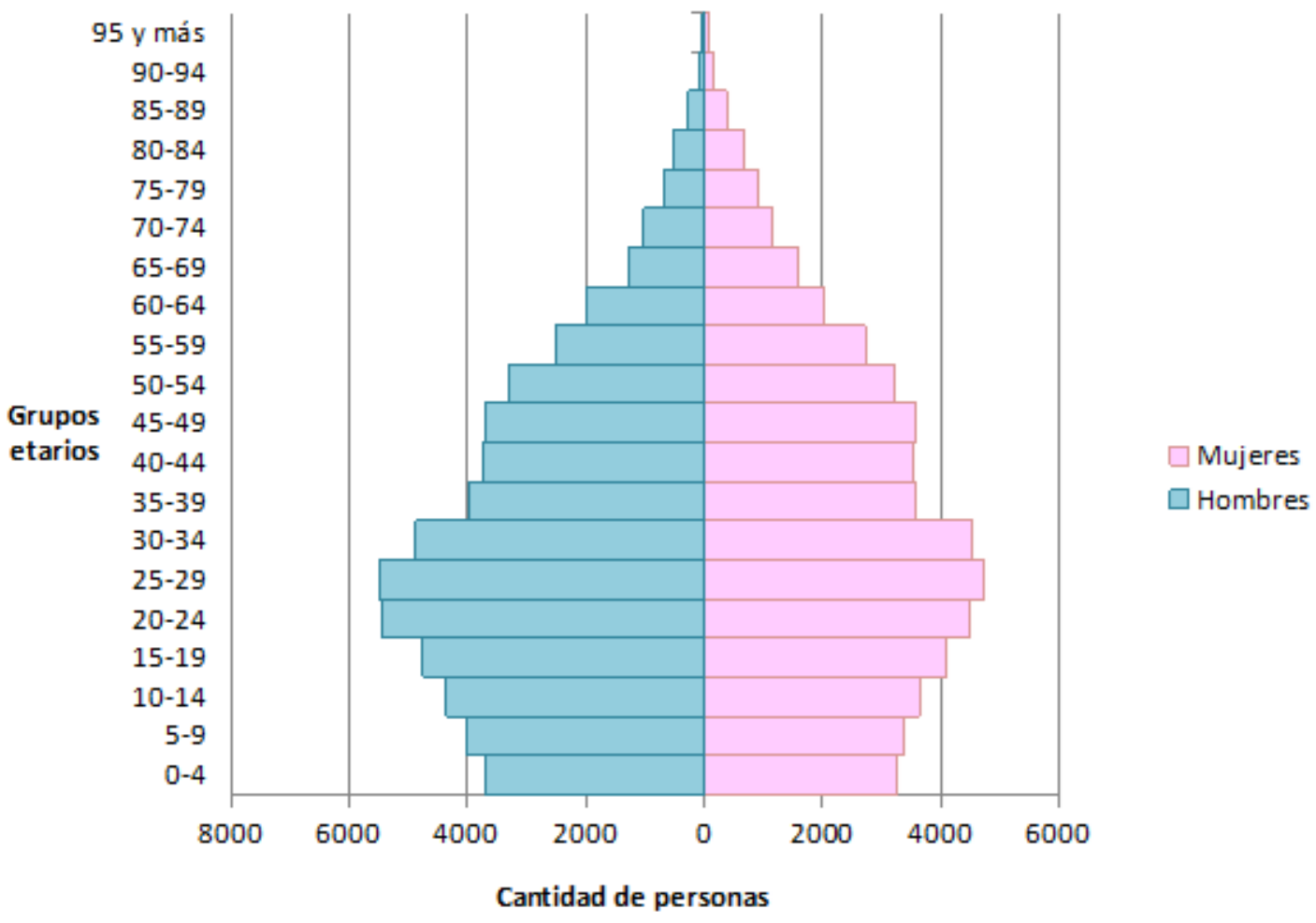

Fuente: INEC, 2011.

En la figura 5 se manifiesta que la distribución de los grupos etarios dentro de la microcuenca, es muy semejante a la pirámide poblacional nacional. La base de la pirámide corresponde con población de menor edad. El grueso de la población, es decir un $28 \%$ corresponde con personas entre los 20 a los 34 años. El grupo etario entre los 25 a los 29 años, representa el casi un 10\% del total de la pirámide.

Finalmente, es importante destacar que en la microcuenca río Burío - quebrada Seca se da una proporción por sexo de aproximadamente, 108 hombres por cada 100 mujeres, sin embargo esta generalización aplica solo para los grupos etarios menores a los 55 años, ya que después de esta edad la proporción hombre - mujer se invierte. Esta proporción difiere totalmente con las tendencias a nivel regional y nacional, ya que la provincia Heredia hay 95 hombres por cada 100 mujeres, mientras que para el país, son 96 hombres por cada 100 mujeres (INEC, 2011). 


\section{Vivienda}

Para el año 2011 la microcuenca del río Burío-quebrada Seca tenía 35411 viviendas (33502 individuales y 1909 colectivas) que alojaban una población de 115776 habitantes, es decir 3.3 personas por vivienda. La distribución espacial manifiesta que las 468 UGM del cantón Heredia concentran el mayor número de viviendas individuales, unas 17606 viviendas (47\% del total). Por otro lado, las 9 UGM del distrito de San Rafael de Alajuela, concentran menos del 2\% de viviendas del área de estudio.

Figura 6. Total de viviendas individuales por tipo de zona, microcuenca del río Burío - quebrada Seca, 2011

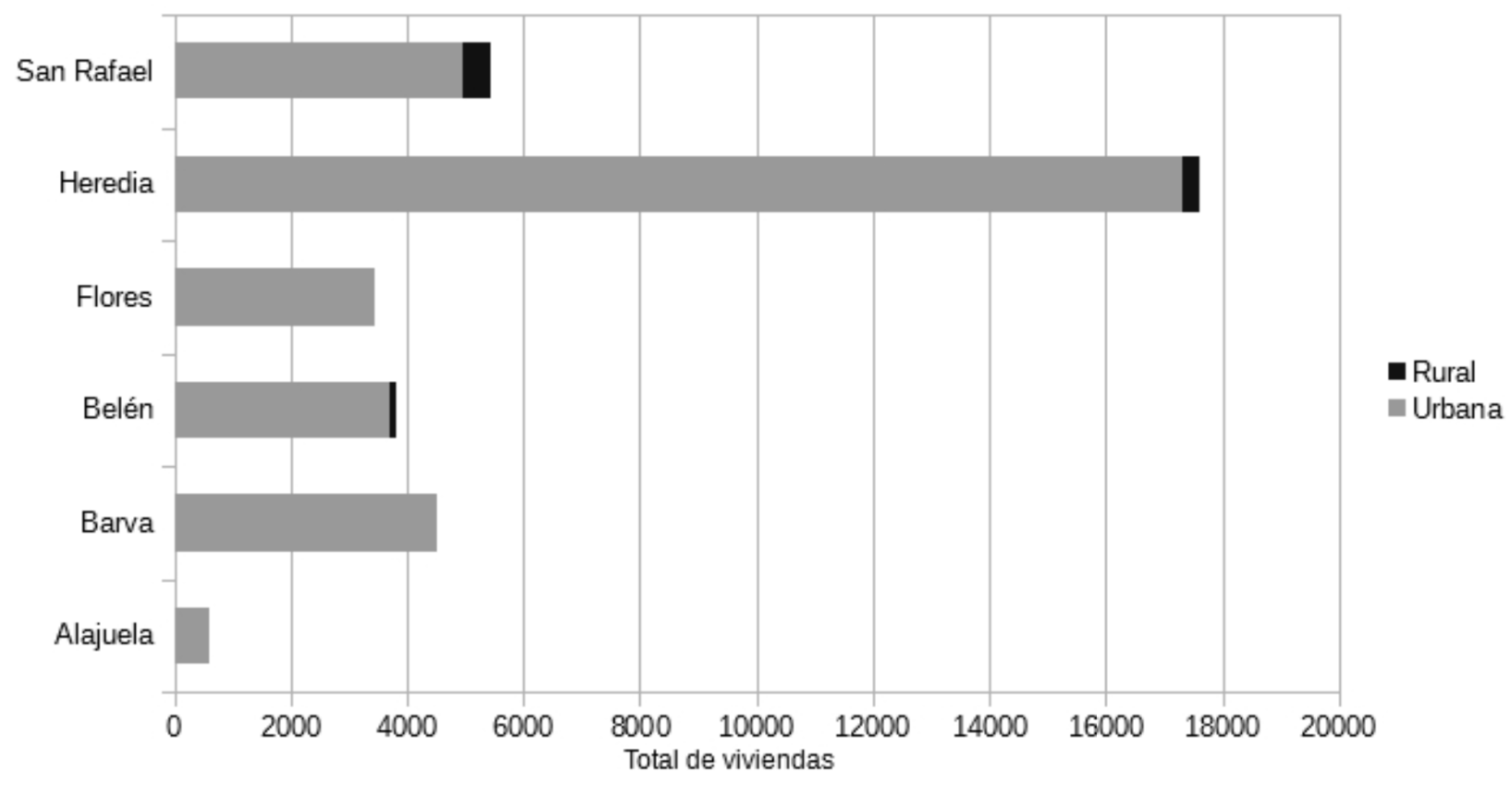

Fuente: INEC, 2011.

Al mismo tiempo hay un predominio de residencias urbanas en la microcuenca, la figura 6 se refleja que el 97,5\% de las viviendas se encuentra en esta zona. Las 35411 viviendas se encuentran distribuidas en unos 80 barrios, residenciales, condominios, comunidades y poblados identificados en la cartografía de PRUGAM y OSM. En detalle, en Barva se ubican 7 comunidades (Barva, San Roque, Don Álvaro, Jardines de Santa Lucía, Malinche Real, Santa Lucía, Villa Esmeralda), San Rafael tiene 16 asentamientos (Aves del Paraíso, Finca El Centro, 
Joaquina, Malecus, Palmar, Paso Viga, Villas Providencia, Ana Victoria, Bajo Los Molinos, Barrio Peralta, Las Angarillas, Las Tinajas, Matasano, Pueblo Bonito, San Josecito, Santísima Trinidad, Villa Sole), el cantón Belén posee 9 (Arbolito, La Asunción, Urbanización Manantiales,Condominio Hacienda Belén,Condominio Haciendas de La Ribera, La Amistad, Labores,San Antonio,Villas de Margot), en Flores hay 8 (Barrio Flores, Cristo Rey, Las Hadas, Llorente, Santa Elena, Urbanización El Rosario, La Plantación, Las Flores, Los Jardines, Santa Marta), en Heredia existen 35 asentamientos principalmente distribuidos en Mercedes y San Francisco) y en el distrito de San Rafael se localiza el barrio El Futuro(figura 7 ).

Figura 7. Paisaje urbano de la microcuenca del río Burío- quebrada Seca
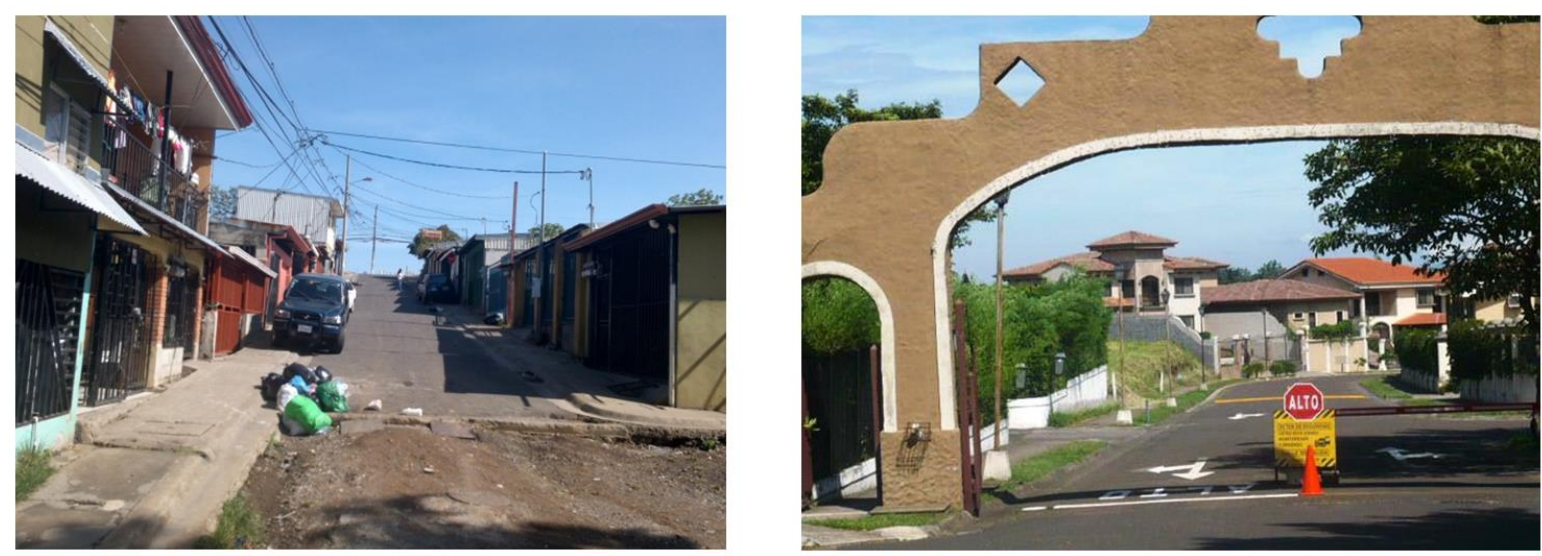

Fuente: Trabajo de campo, 2016.

Es importante enfatizar el gran avance urbano que ha experimentado el área inmediata a la microcuenca, aprovechando el sistema de zona franca, la cercanía al Aeropuerto Internacional Juan Santamaría y la autopista General Cañas (Ruta 1), el aumento de proyectos residenciales y comerciales en los últimos años, por lo que las zonas rurales han sido contraídas.

Entre las industrias más significativas dentro del área de estudio están: Hewllett-Packard, Bourns Trimpot, Abbott Laboratorios, Global Park, Firestone, Amanco, Pedregal. Además, de hoteles y complejos deportivos como: Marriott, Proyecto Goal de la FIFA, Polideportivo de Belén, varios centros recreativos y comerciales. 
Figura 8. Avance urbano en la microcuenca del río Burío-quebrada Seca
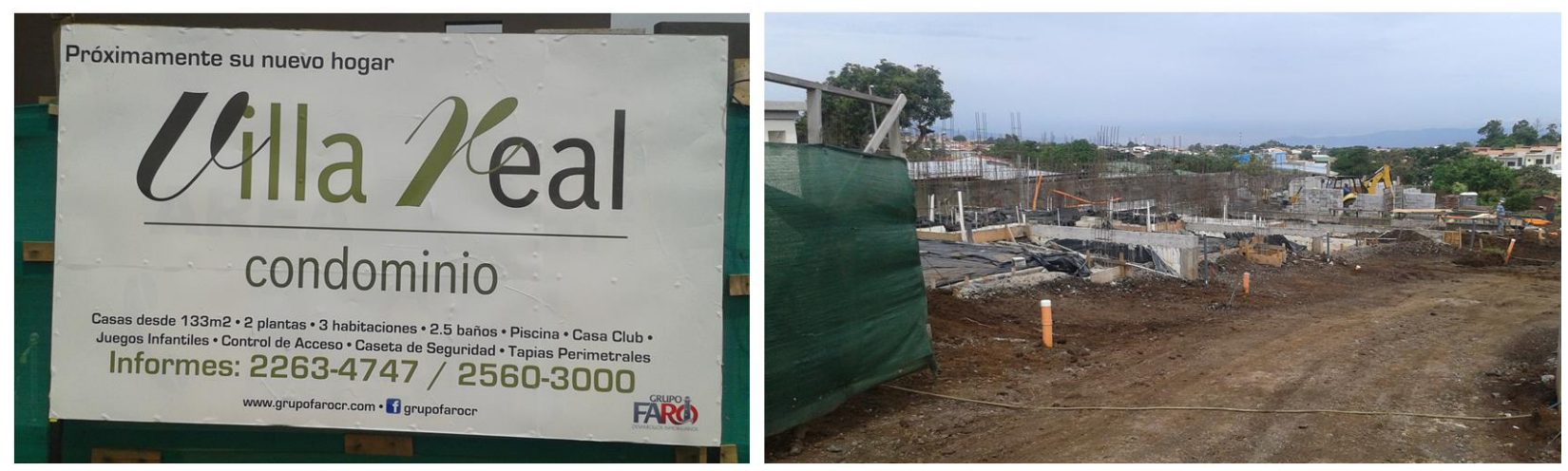

Fuente: Trabajo de campo, 2016

Por otro lado, menos de 1000 viviendas se ubican en la zona rural. El 55\% se distribuyen en San Rafael de Heredia. Específicamente para las UGM del distrito de los Ángeles existen 31 viviendas rurales por cada 100 viviendas urbanas. El 45\% restante de viviendas rurales están dispersas en Belén y Heredia, aproximadamente 391 casas.

De la misma manera, a partir del último Censo de Población y Vivienda (2011), se determinó el tipo de viviendas ubicadas dentro de la microcuenca río Burío - quebrada Seca. La siguiente tabla 5 resume la clasificación de tipos de vivienda. 
Tabla 5. Tipo y cantidad de viviendas individuales en las 814 UGM en la microcuenca río Burío - quebrada Seca, 2011

\begin{tabular}{|c|c|c|c|c|c|c|c|c|}
\hline Cantón & $\begin{array}{c}\text { Casa } \\
\text { independie } \\
\text { nte }\end{array}$ & $\begin{array}{c}\text { Casa } \\
\text { independi } \\
\text { ente en } \\
\text { condomini } \\
\quad \text { o }\end{array}$ & $\begin{array}{c}\text { Edificio de } \\
\text { apartame } \\
\text { ntos }\end{array}$ & $\begin{array}{c}\text { Edificio de } \\
\text { apartamen } \\
\text { tos en } \\
\text { condomini } \\
\quad \text { o }\end{array}$ & $\begin{array}{l}\text { Cuart } \\
\text { o en } \\
\text { cuarte } \\
\text { ría }\end{array}$ & $\begin{array}{c}\text { Tugu } \\
\text { rio }\end{array}$ & $\begin{array}{c}\text { Otr } \\
\text { o }\end{array}$ & Total \\
\hline Alajuela & 546 & 0 & 9 & 0 & 2 & 15 & 0 & 572 \\
\hline Barva & 4047 & 19 & 244 & 0 & 5 & 7 & 8 & 4330 \\
\hline Belén & 3042 & 266 & 239 & 12 & 33 & 1 & 5 & 3598 \\
\hline Flores & 3073 & 11 & 174 & 3 & 10 & 5 & 10 & 3286 \\
\hline Heredia & 13652 & 1274 & 1546 & 54 & 39 & 24 & 31 & 16620 \\
\hline \multicolumn{9}{|l|}{ San } \\
\hline Rafael & 4751 & 73 & 233 & 3 & 23 & 9 & 4 & 5096 \\
\hline Total & 29111 & 1643 & 2445 & 72 & 112 & 61 & 58 & 33502 \\
\hline
\end{tabular}

Fuente: INEC, 2011.

Casi un $87 \%$ de las viviendas del área de estudio corresponde con casas independientes. Heredia concentra 13652, es decir, casi la mitad del total de viviendas de este tipo y menos del 8\% de las viviendas de tipo independiente se localizan en Alajuela.

Ocupando el segundo lugar, los edificios de apartamentos, representan un 7\% del total de las viviendas y en tercer lugar se encuentran la casa independiente dentro de un condominio, alcanzando casi el 5\% del total de viviendas. Es importante mencionar que la mayoría de estos dos últimos tipos de vivienda se localizan en el distrito de Heredia (1274 y 1546 respectivamente), esto hace referencia al gran avance residencial de la zona debido a la construcción de estos proyectos residenciales. 
Los otros tipos de vivienda catalogados como edificio de apartamentos en condominio, cuartos en cuartería, tugurios y otros representan poco menos del $1 \%$ del total de viviendas dentro de la microcuenca.

Estos resultados difieren parcialmente de los porcentajes a nivel regional y nacional, donde las casas independientes, aunque siempre serán la mayoría de viviendas, forman, aproximadamente, un $91 \%$ y un $93 \%$ respectivamente del total. Es necesario otorgar parte del porcentaje a los proyectos residenciales que se han construido especialmente en Heredia, lo cual hace que las viviendas independientes bajen su porcentaje, aunque continúan ocupando el primer lugar. Sin embargo, las viviendas en edificios de apartamentos y las casas independientes en condominios, se ubican como el segundo y tercer lugar, respectivamente, dentro de los tipos de viviendas más comunes a nivel regional y nacional (INEC, 2011).

La presencia de tugurios en la microcuenca es muy baja, pues constituyen menos del $0.2 \%$ del total de viviendas, es decir menos de 100 viviendas distribuidas en 24 UGM. A nivel regional, Heredia es la provincia como menos asentamientos en condición de precarios con 13 de 400 presentes en el país (MIVAH, 2005).

El Futuro en San Rafael de Alajuela, es uno de los pocos precarios en el área de estudio. Este barrio fue fundado en 1991, se extiende unas 6 ha y para el año 2011 vivían aproximadamente 1232 personas(figura 9). 
Figura 9. Asentamiento urbano El Futuro con presencia de tugurios en la microcuenca

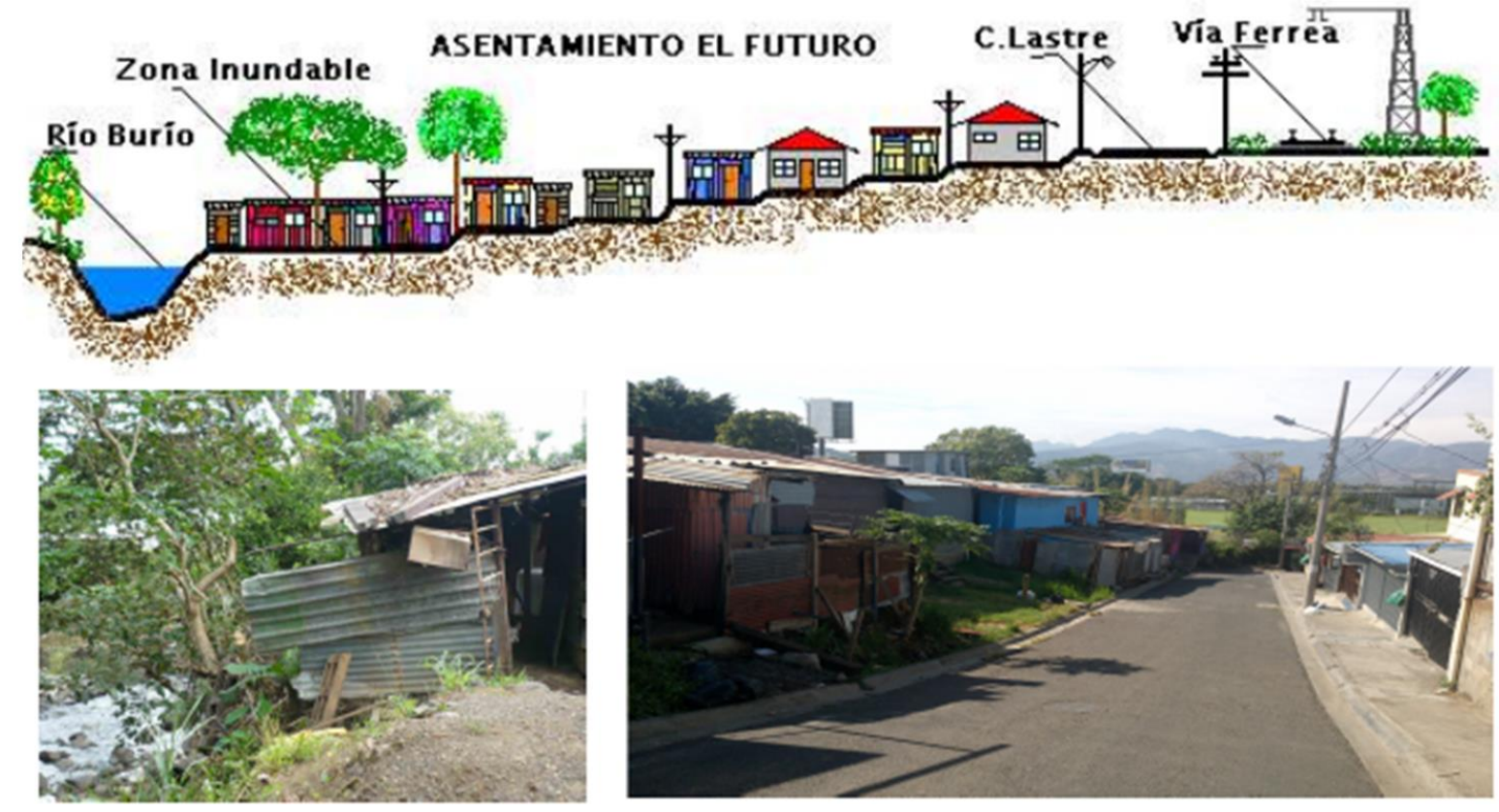

Fuente: MIVAH, 2005 y trabajo de campo, 2016.

Manejo del agua

Dadas las problemáticas más frecuentes de esta microcuenca (inundaciones, contaminación de aguas por basura, conexiones ilegales de aguas, entre otros). Por medio del censo 2011 se identificó dónde y cuáles UGMS tienen problemas con el manejo del agua (fuente, consumo, tratamiento de aguas negras y servidas) y residuos sólidos y orgánicos (reciclaje, recolección de basura, tratamiento, otros) en las 35411 viviendas del área de estudio.

Respecto a la procedencia del agua para consumo en viviendas, la cobertura es muy alta con acueductos de origen municipal, de Asociaciones administradoras de los Sistemas de Acueductos y Alcantarillados comunales (ASADAS) o empresa, cerca del 98\%. El principal proveedor regional es la ESPH, que abastece 66580 clientes en los siguientes sectores y con los siguientes servicios: cantón Heredia, cantón San Rafael, Barva (Sector de Santa Lucía) y cantón Flores. 
Por el contrario, el abastecimiento por río, quebrada, camión cisterna, acumulación por lluvia son casos relativamente puntuales en el área de estudio. Son menos de 100 viviendas que se encuentran distribuidas en 37 UGM.

Tabla 6. Procedencia de agua fuera del sistema de acueductos en la microcuenca

\begin{tabular}{|l|l|r|}
\hline Cantón & Procedencia del agua & Cantidad \\
\hline Barva & Pozo & 1 \\
& & 2 \\
& & 1 \\
\cline { 2 - 3 } & Rio o quebrada & 1 \\
\cline { 2 - 3 } & Otra fuente & 1 \\
\hline \multirow{4}{*}{ Belén } & Pozo & 6 \\
& & 4 \\
\cline { 2 - 3 } & Otra fuente & 1 \\
\hline Flores & Pozo & 21 \\
& & 2 \\
\cline { 2 - 3 } & Río o quebrada & 1 \\
\hline \multirow{4}{*}{ Heredia } & Pozo & 1 \\
& & 4 \\
& & 4 \\
\cline { 2 - 3 } & Otra fuente & 11 \\
& & 1 \\
\hline \multirow{3}{*}{ San Rafael } & Pozo & 1 \\
\cline { 2 - 3 } & Río o quebrada & 1 \\
\cline { 2 - 3 } & Otra fuente & 66 \\
\hline \multicolumn{2}{|l|}{ Total de viviendas } &
\end{tabular}

Fuente: INEC, 2011.

Por otra parte, la disponibilidad de servicio sanitario y la disposición de aguas es un indicador ambiental muy importante en esta microcuenca, por la variabilidad de espacios degradados (malos olores, aguas jabonosas, basura en el río). Desde 2007, el Laboratorio de Análisis Ambiental ha muestreado y realizó un inventario puntual de desfogues en los cuerpos de agua del cantón Belén, especialmente el río Burío, donde han detectado puntos de alta contaminación por la escorrentía urbana y las descargas de aguas residuales y negras(tabla 6).

Según el censo 2011, para el área de estudio aproximadamente 190 viviendas no cuentan con alcantarillado sanitario o tanque séptico, distribuidas en 82 UGM. Es decir, las aguas negras y residuales son dispuestas directamente a ríos, quebradas, zanjas o huecos(figura 10). 
Figura 10. Desfogues y conexiones ilegales en los ríos de la microcuenca

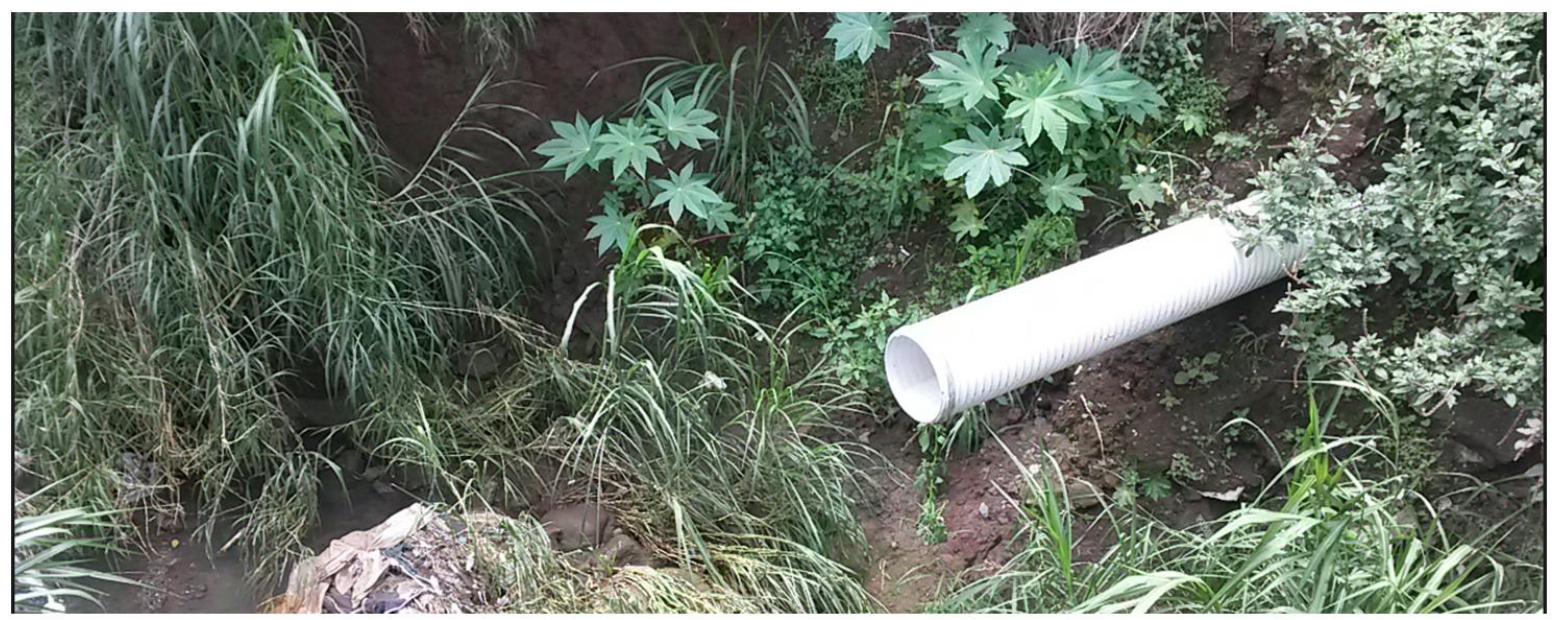

Fuente: Trabajo de campo. 2015.

Manejo de desechos sólidos

Cerca de 61 viviendas no tienen servicio de recolección de basura por camión, es decir los desechos sólidos se botan en un río, quebrada, lote baldío, entierra o queman. Históricamente, las obstrucciones por acumulación de material o basura en el río han sido un problema en los puentes, originando la pérdida de capacidad hidráulica en ciertos tramos en consecuentemente se presentan anegamientos, igualmente el propio cauce posee corrientes rápidas que arrastran elementos como piedras, troncos, basura; estos pueden impactar cualquier tipo de edificación o puente (figura 11,12 y 13 ). 
Figura 11. Obstrucción del flujo del río Burío en puente por desechos sólidos y orgánicos en crecida del 2007

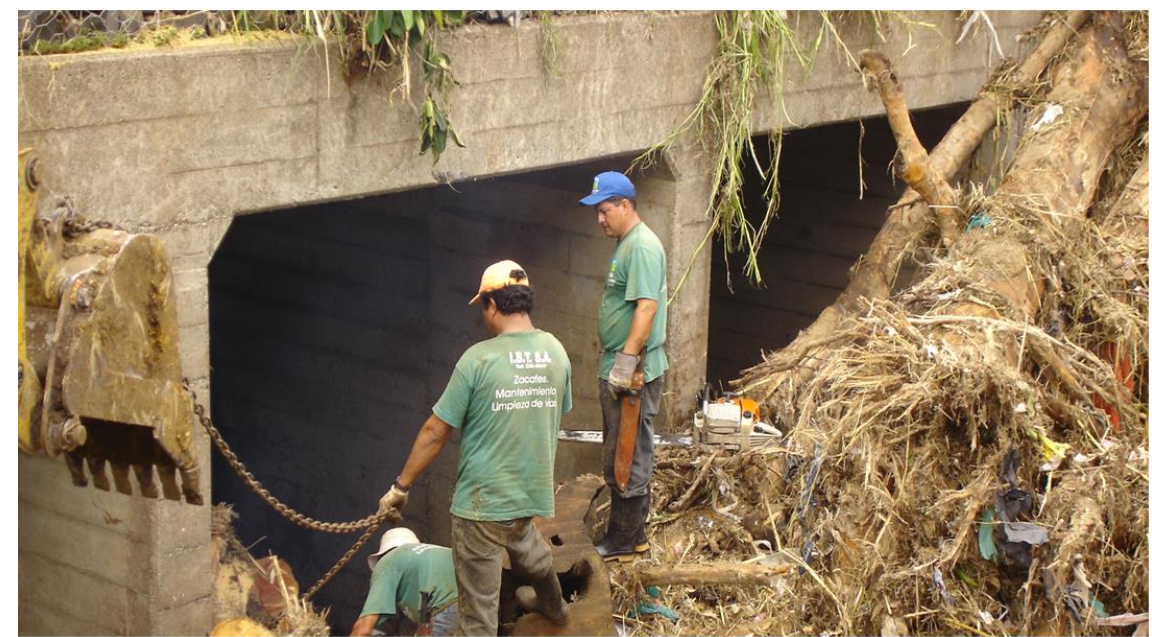

Fuente: Municipalidad de Belén, 2007.

Figura 12. Cantidad de viviendas sin recolección de basura y desechos sólidos

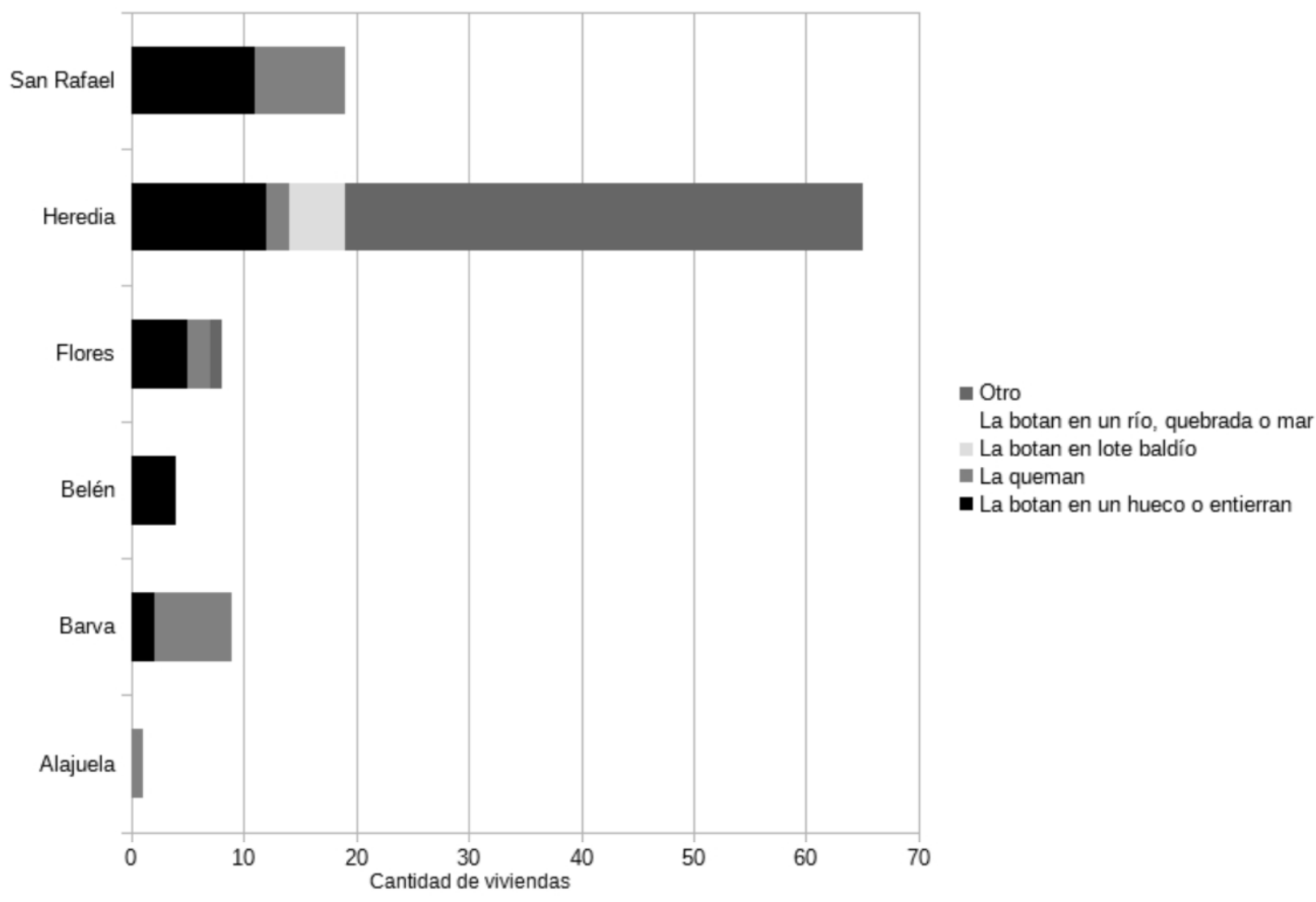

Fuente: INEC, 2011. 
Figura 13. Señalización de regulación y sensibilización ambiental en Mercedes Norte

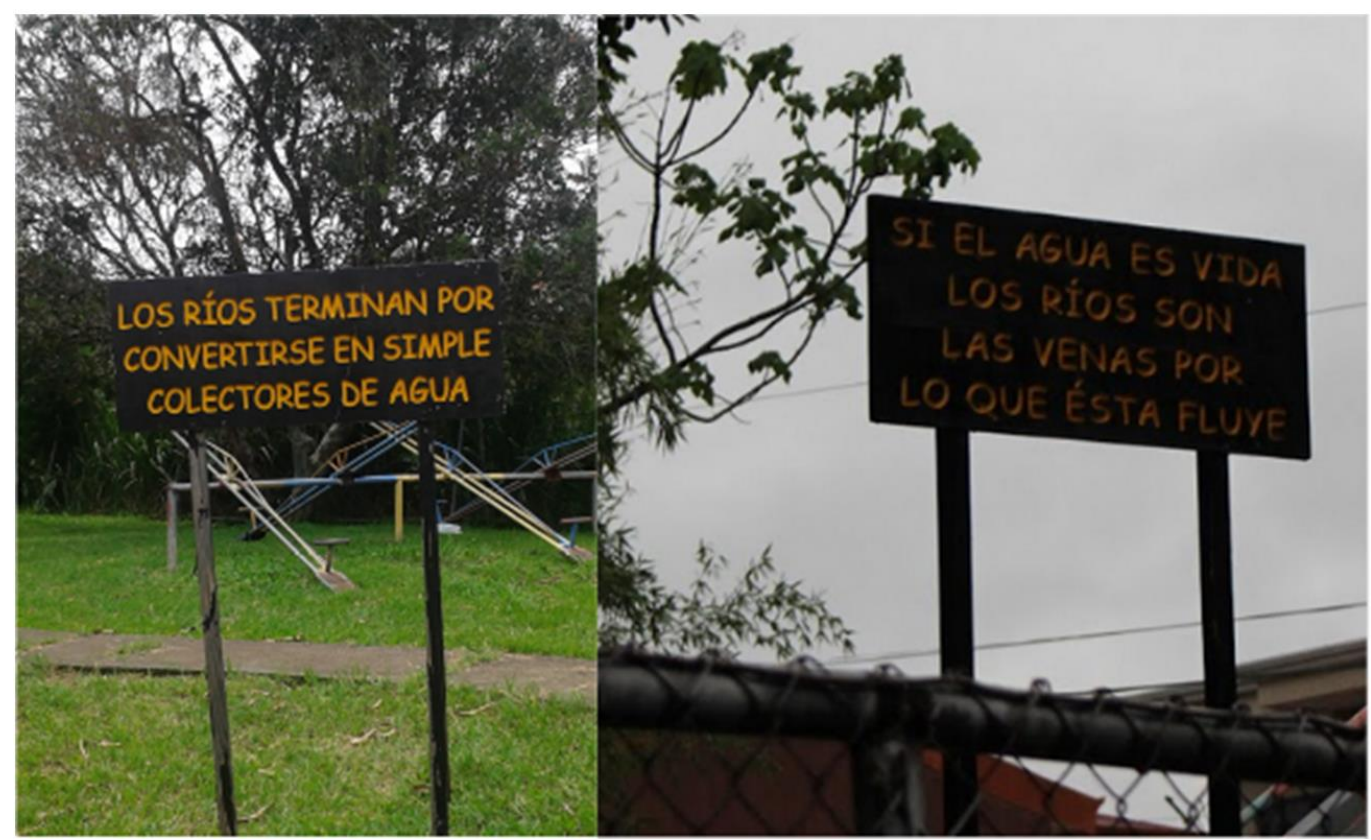

Fuente: Trabajo de campo, 2016.

De la misma manera, el censo 2011 consultó acerca de la separación de los desechos sólidos (plástico, vidrio, aluminio, papel, restos orgánicos) en las viviendas. La separación de desechos consiste en dar un tratamiento diferenciado a los residuos, siempre y cuando esa disciplina haya sido adoptada en la vivienda y forme parte del manejo integral de residuos.

En general, en 2011 la separación de desechos sólidos en las viviendas individuales era mayor al $50 \%$ de los casos. Para materiales reciclables como: plástico, vidrio, aluminio y papel, entre 17265 y 18072 viviendas clasificaban estos materiales de otros. Y para residuos orgánicos el 68\% de las viviendas (unas 22785) separaban cáscaras, huesos, frutas, verduras dirigido a la producción de abono orgánico(figuras 14, 15 y 16). 
Figura 14. Separación de desechos orgánicos en la microcuenca del río Burío por vivienda

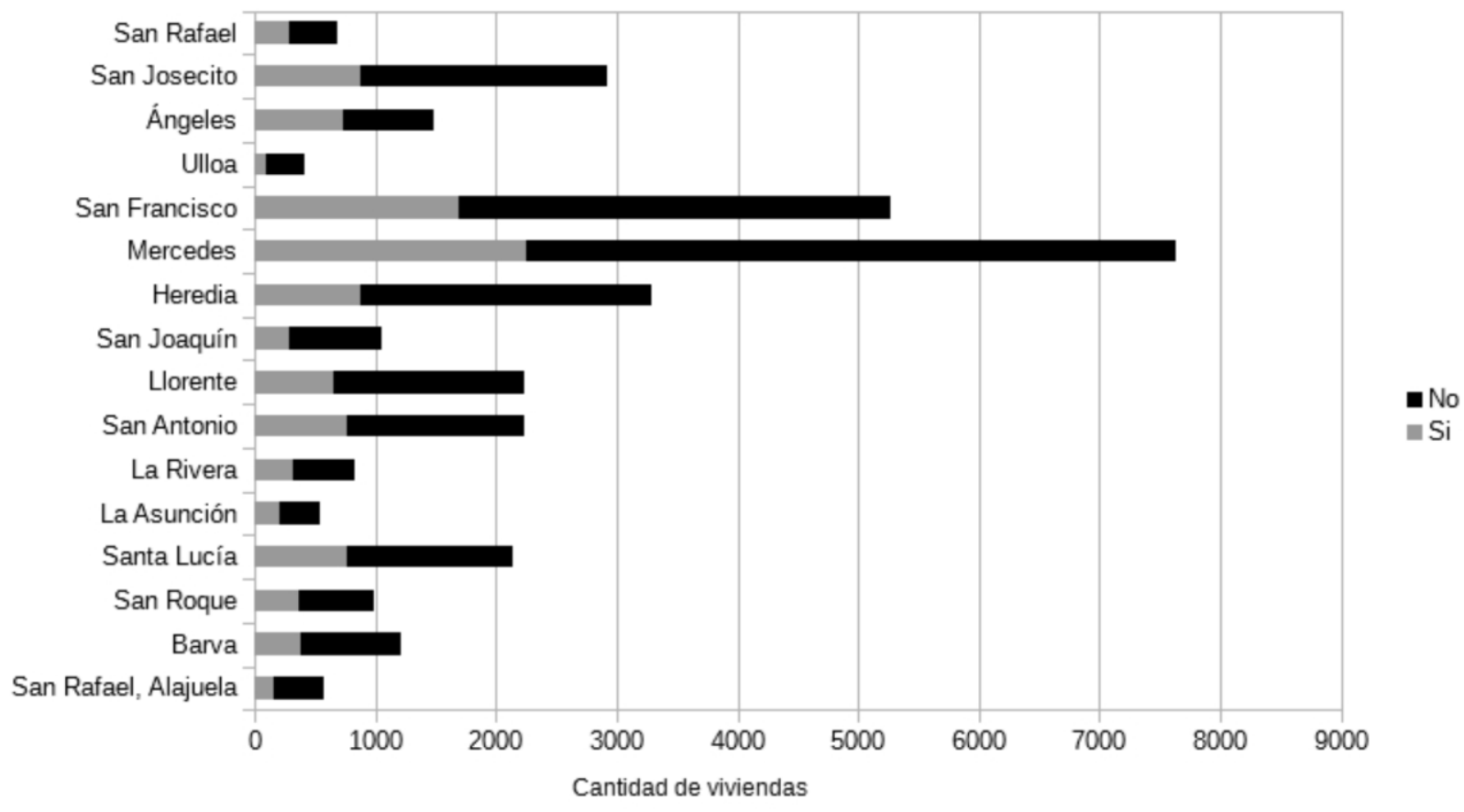

Fuente: INEC, 2011.

Figura 15. Separación de materiales reciclables en Asunción, Los Ángeles y Heredia

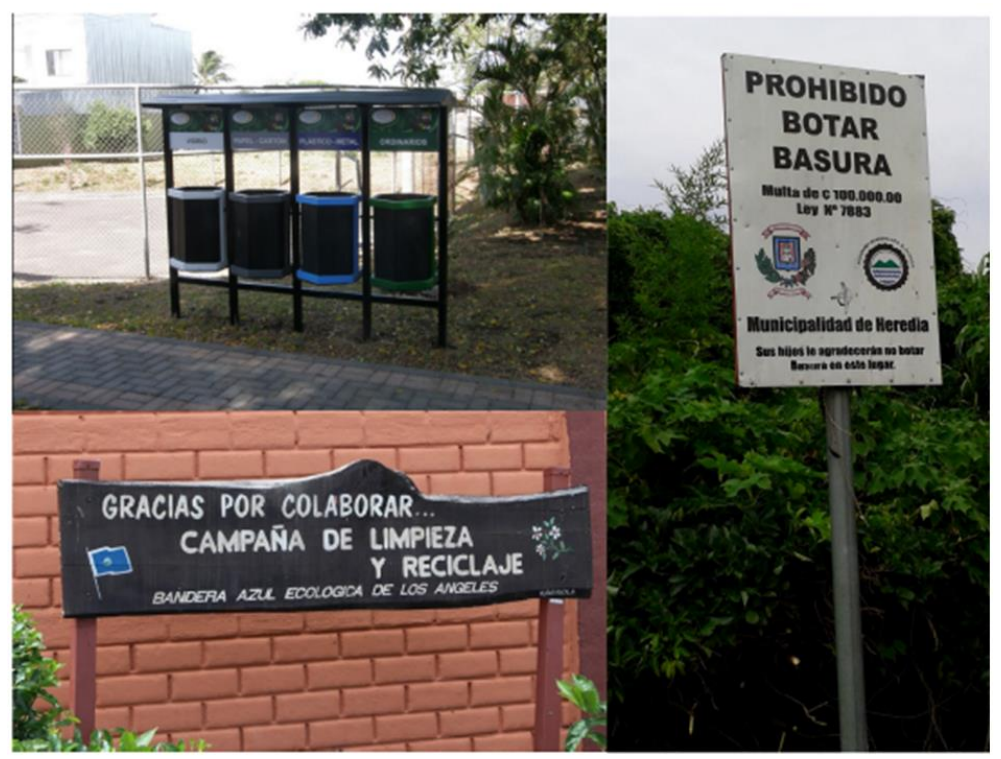

Fuente: Trabajo de campo, 2016. 
Figura 16. Separación de materiales reciclables en la microcuenca del río Burío por vivienda

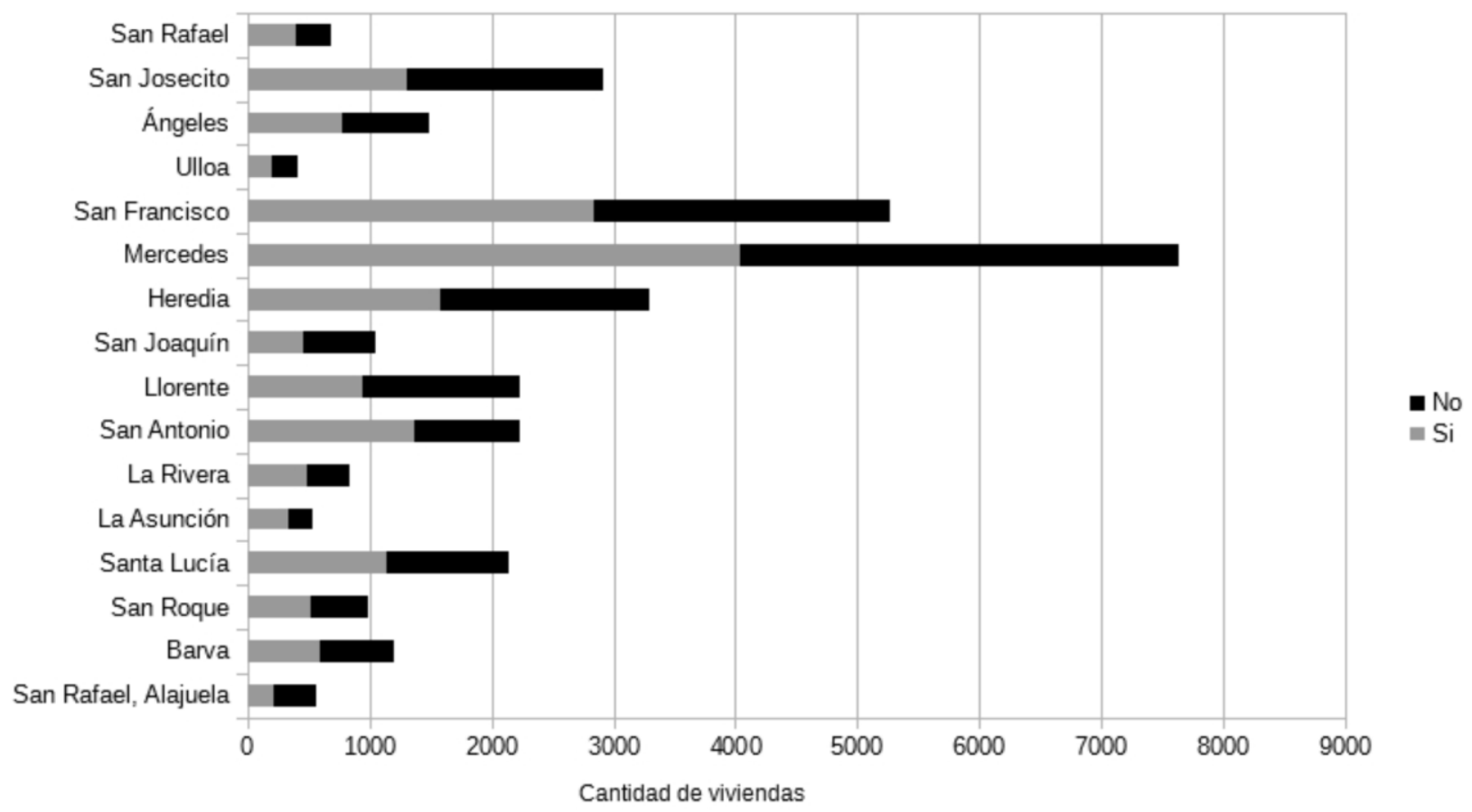

Fuente: INEC, 2011.

Cartografía participativa, divulgación de resultados con actores locales y habitantes de la microcuenca

Con el fin de divulgar y recopilar las percepciones de las comunidades, actores sociales y habitantes de la microcuenca respecto a las problemáticas, potencialidades ambientales y sociales, se recurrió a implementar un sondeo, por medio de un Geoform de ArcGis Online (http://arcg.is/1UCNVMR).

La difusión del sondeo se realizó por medio de correo electrónico, redes sociales y visitas a las ADI del área de estudio durante varios meses del 2016. Para la divulgación se tomó en cuenta una diversidad perfiles o páginas de redes sociales como: asociaciones de desarrollo integral, grupos de vecinos, periódicos locales, grandes empresas (por ejemplo: ESPH), municipalidades, otros(figuras 17, 18, 19, 20 y 21). 
Figura 17. Sondeo dirigido a los habitantes de la microcuenca del río Burío-quebrada Seca

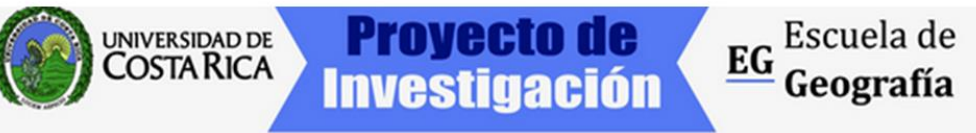

Estimado (a) vecino (a):

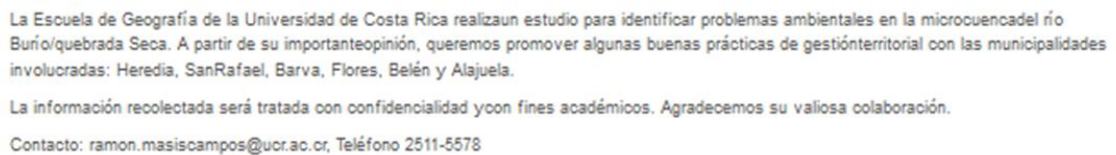

Contacto: ramon.masiscampos @ucr.ac.cr, Teléfono 2511-5578

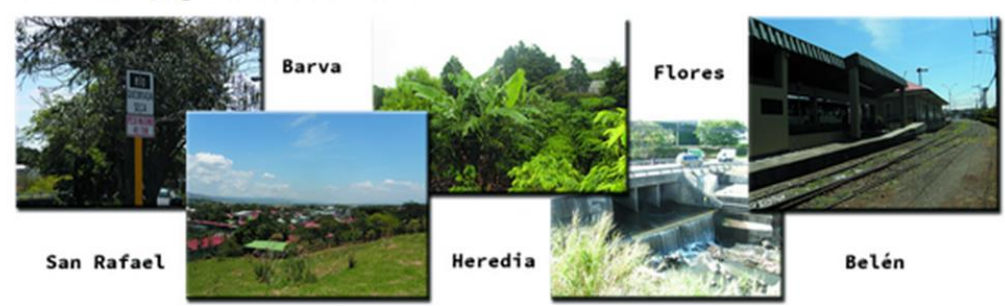

1. Introducir información

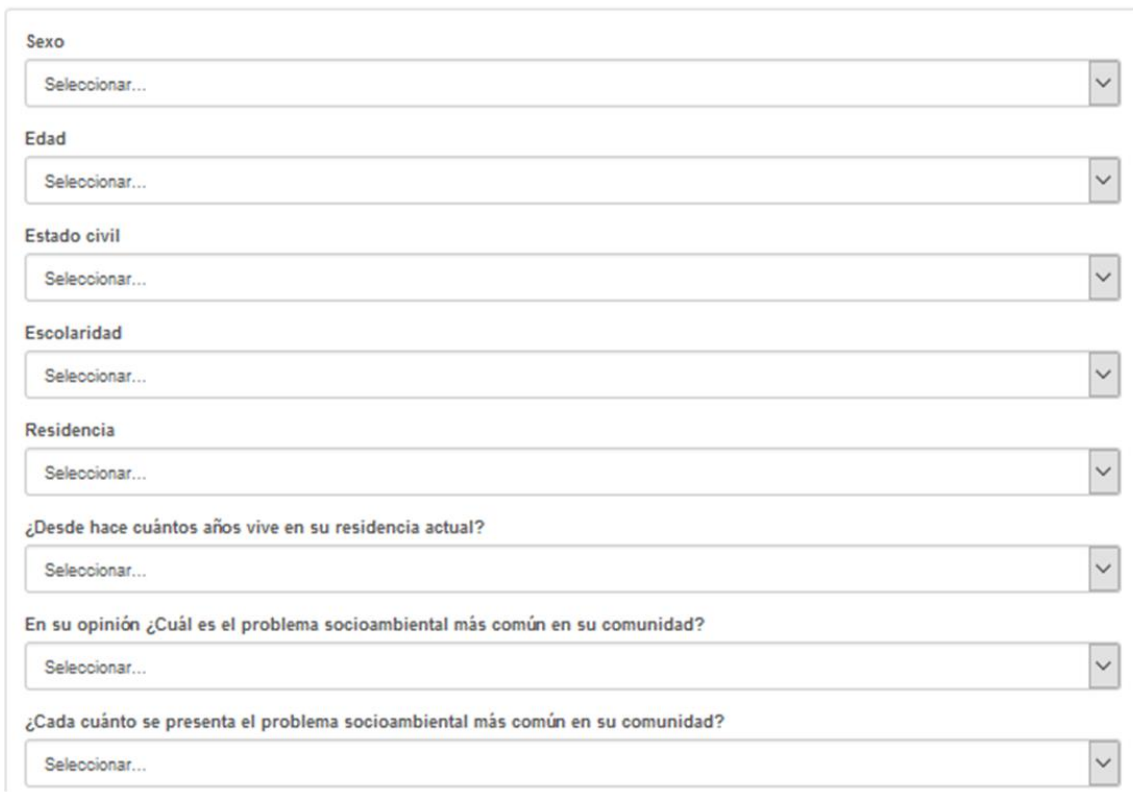

Fuente: Elaboración propia.

El sondeo se estructuró para colectar el perfil de la persona (sexo, edad, estado civil, escolaridad, residencia) y la situación que deseaba reportar (problema socioambiental: inundación, anegamiento, contaminación por aguas negras o servidas, deforestación, invasión zonas protectoras, deslizamientos, pérdida de biodiversidad, malos olores, otros), frecuencia del problemas socioambiental (diario, semanal, mensual, anual, permanente), entidad a la que acude para resolver el problema (Municipalidad, Ministerios, ADI, otros). Finalmente, opcionalmente la 
persona puede adjuntar al sondeo fotografía, videos o documentos que considere necesario reportar la problemática y su ubicación.

\section{Figura 18. Difusión del sondeo por redes sociales dirigido a los habitantes de la microcuenca}

Provincia cuatro

15 de junio -6

Estimado (a) vecino (a) de San Rafael, Barva, Heredia, Flores y Belén:

La Escuela de Geografia de la Universidad de Costa Rica realiza un estudio para identificar problemas ambientales en la microcuenca del rio Burio/quebrada Seca. A partir de su importante opinión, queremos promover algunas buenas prácticas de gestión territorial con las municipalidades involucradas: Heredia, San Rafael, Barva, Flores, Belén y Alajuela.

La información recolectada será tratada con confidencialidad y con fines académicos. El sondeo está disponible en http://arcg.is/1UCNVMR

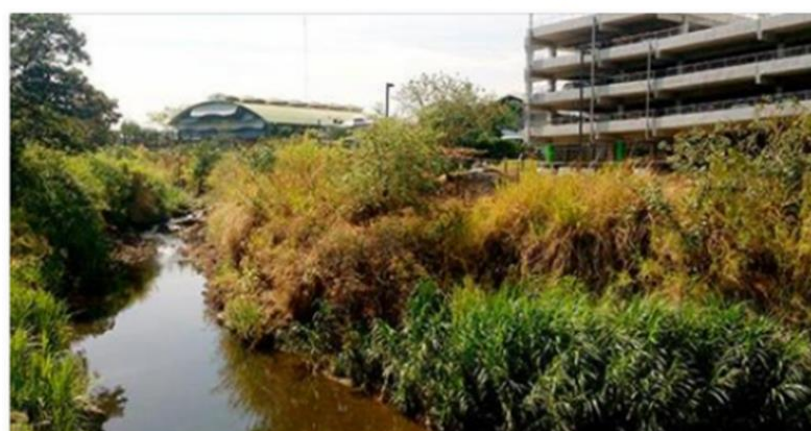

Sondeo dirigido a los habitantes de la microcuenca del río Burío-quebrada Seca

Resumen: La Escuela de Geografia de la Universidad de Costa Rica realiza un estudio académico dirigido a los habitantes de la microcuenca del río...

GEOGRAFIA-UCR.MAPS.ARCGIS.COM

If Me gusta $\quad \Rightarrow$ Comentar $\Rightarrow$ Compartir

Errol Gonzalez Carvajal, María Elena Argüello y 3 personas más
Radio Barva ha añadido 4 fotos nuevas

$9 n-8$

Lluvia torrencial en Barva de Heredia esta tarde de jueves. Mucho cuidado. (fotos Shiney Herrera).
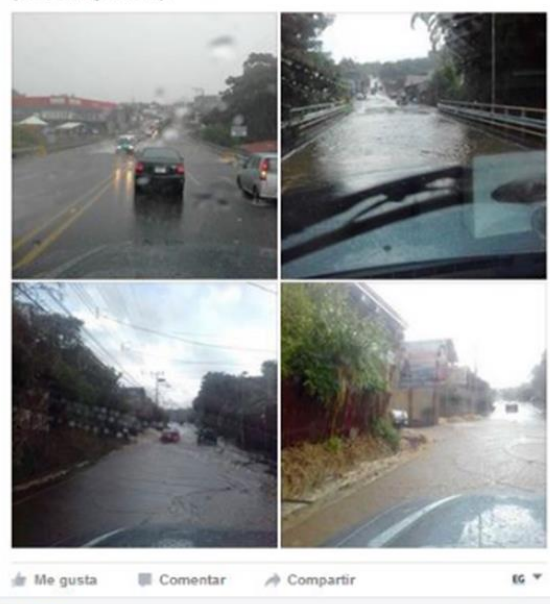
O8 469

4 veces compartido

EG EG Geografía UCR Estimado (a) vecino (a) de Barva: estudio para identificar problemas ambientales en la mirocuenca del rio Buria/quebrada Seca. A partir de su importante opinión, queremos promover algunas buenas prácticas de gestión territorial con las
municipalidades involugradas: Heredia. San Rafael, Bava. Flores. municipalidades
Belén y Alajuels. Belén y Alajuels.

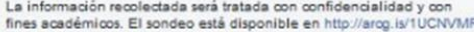
Aoradecemos su valiosa colsboración. Contacto: ramon.masiscamposeguc.sc $\alpha$, Telétono 2511.5578 Me gusta Responder Comentado por

Maroo Montero Ese puente nuevo se volvió una pisana los automóviles no podian pasar.

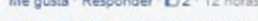
Angie Miranda Bava estaba aguacero greado con mucho viento
Me gusta Responder $B_{1} \cdot 18$ horas

Fuente: Elaboración propia. 
Figura 19. Archivos adjuntos de los reportes del sondeo aplicado por redes sociales

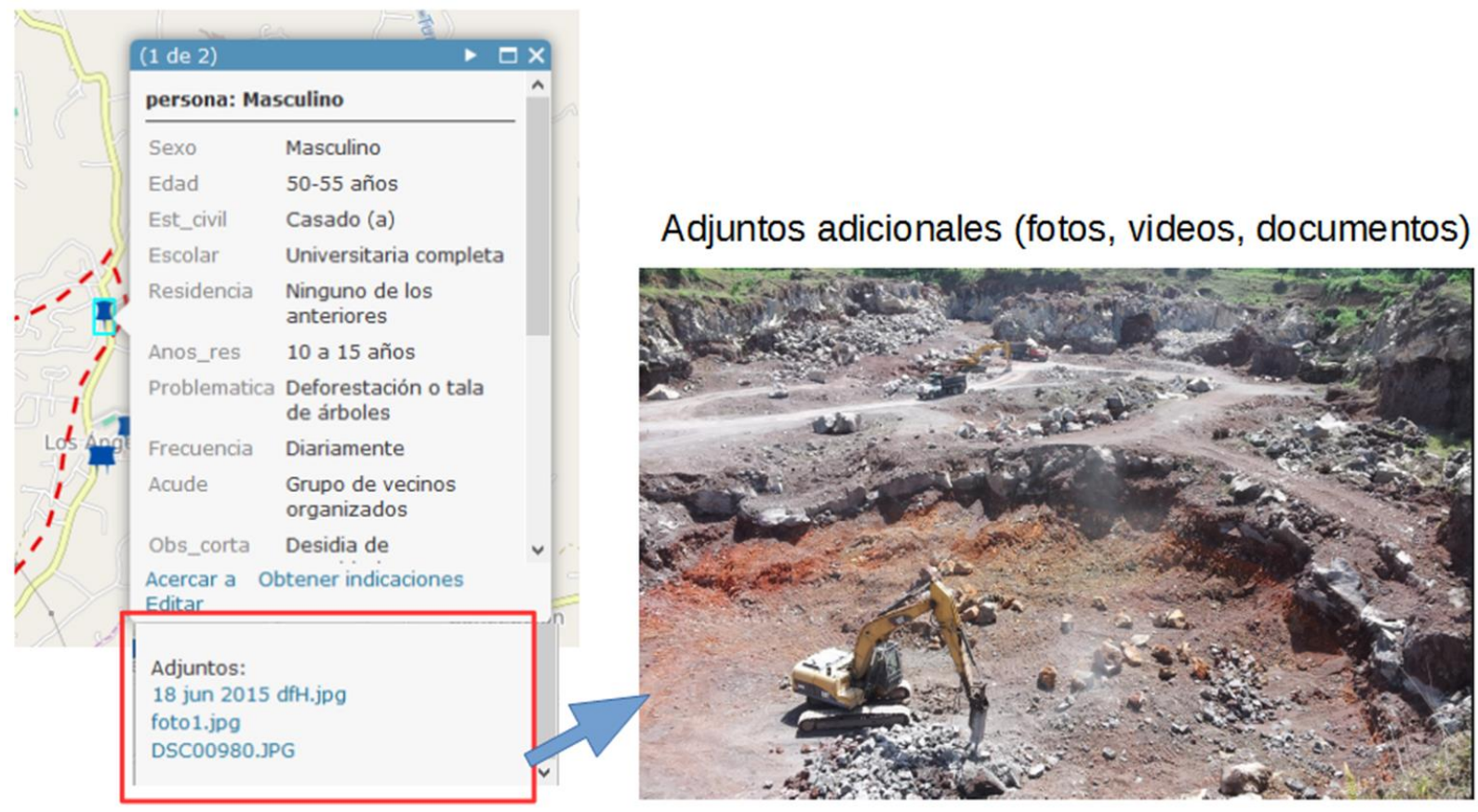

Fuente: Elaboración propia.

Figura 20. Distribución de reportes asociados al sondeo aplicado a los habitantes de la microcuenca.

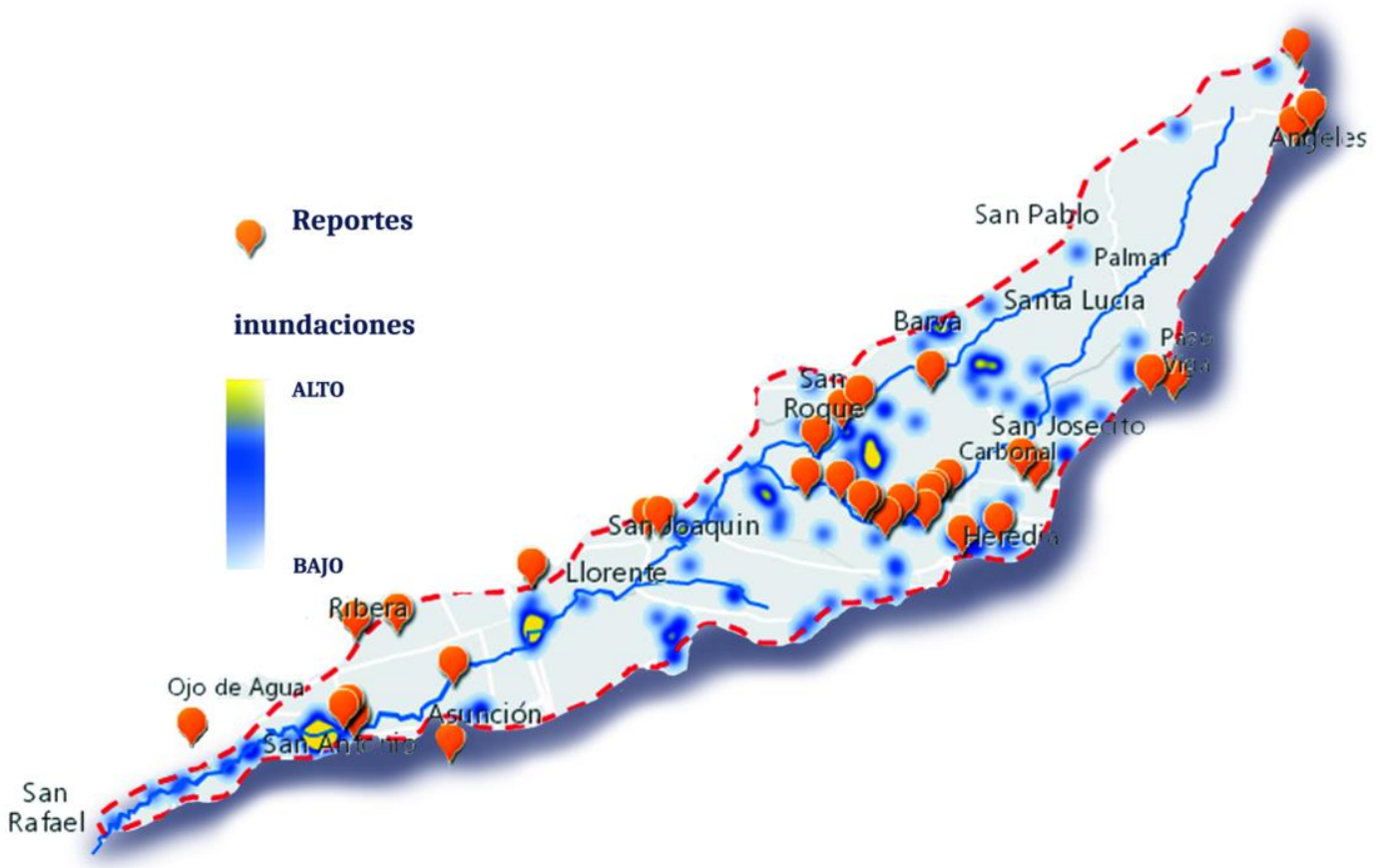

Fuente: Elaboración propia. 
Finalmente, para transferir los resultados y aportes del proyecto con actores de las comunidades, se organizó y participó en el foro-taller Conflicto ambiental: apropiación social y territorialidades en la microcuenca del río Burío-quebrada Seca, celebrado el 5 de octubre de 2016 en Heredia. Con el fin de mostrar un app http://arcg.is/2dnPzFf tipo storymaps, utilizando ArcGis online. Igualmente se realizaron unas infografías del proyecto.

Figura 21. Vista del storymaps dirigido a los habitantes de la microcuenca

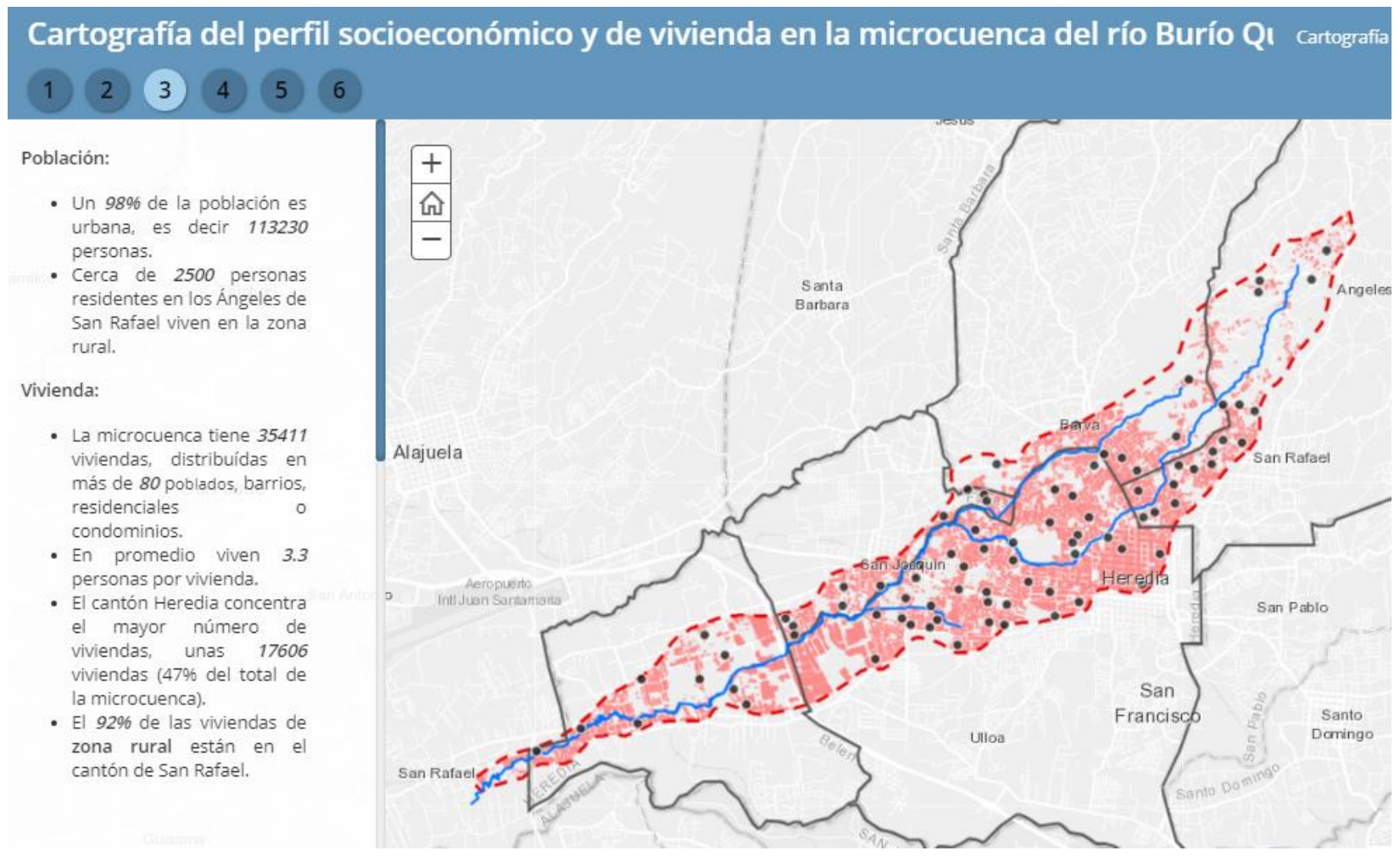

Fuente: Elaboración propia.

Cuando el ser humano ha ocupado estas áreas para desarrollar sus actividades socioeconómicas y se presentan desbordamientos, impactan como pérdidas económicas, sociales o ambientales, especialmente en espacios densamente poblados.

Densidad poblacional y amenaza por inundación

La microcuenca alta se caracteriza por presentar baja densidad poblacional y baja densidad por inundación, sin embargo, como se puede observar en la figura 22 han existido importantes eventos de inundación entre 2000 y 2007 cercanos a las comunidades de los Ángeles, Getsemaní y el Palmar todos pertenecientes al cantón de San Rafael. 
Figura 22. Densidad de población y amenaza por inundación

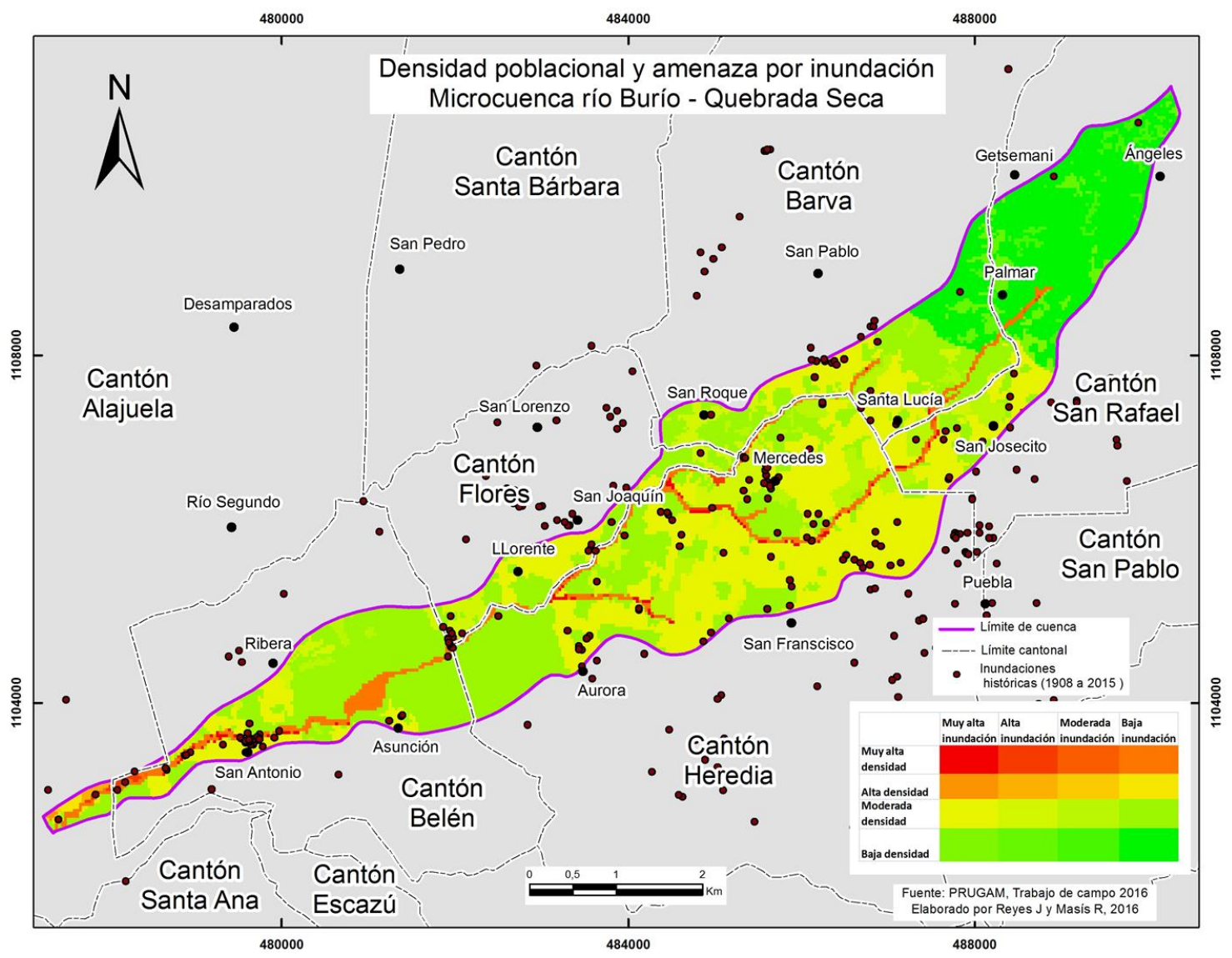

Fuente: Elaboración propia, 2016.

A nivel de la microcuenca media la comunidad de Mercedes presenta una alta cantidad de eventos de inundación las cuales fueron registradas entre el 2001 al 2015, dicha comunidad se encuentra en una zona de moderada densidad y de amenaza moderada de inundación.

Otro punto importante sobre cantidad de eventos de inundación es el que se encuentra entre los límites cantonales de Belén, Heredia y Flores donde se registran eventos desde 1928 hasta el 2013 en un zona de moderada densidad población.

Por último, en la microcuenca baja presenta una cantidad considerable de eventos en el sector de San Antonio de Belén, sector que se caracteriza por presentar mayores áreas en la categoría de alta amenaza por inundación. 
En la microcuenca baja se tienen registros desde 1908 al 2012 siendo el 2004 con el mayor número de eventos con un total de 7 eventos que van desde inundaciones, inestabilidad de cauce hasta lluvias intensas. Los meses donde se han presentado la mayor cantidad de eventos fueron dados durante los meses de septiembre y octubre, sin embargo a inicios del siglo XX se dieron algunos eventos durante el mes de enero.

Entre los daños a la infraestructura se encuentran daños a puentes, caminos, casas dañadas y anegadas, vehículos afectados, pozos de agua contaminados y la generación de muros falseados y caídos.

A nivel de las enfermedades el dengue, cólera, paludismo o leptospirosis son algunas de las llamadas "enfermedades sujetas a vigilancia epidemiológica nacional e internacional", cuando ocurren inundaciones. El problema se agudiza cuando se mezclan las aguas pantanosas y las aguas negras poniendo en mayor riesgo, la salud humana. Si bien, en el área en estudio no se tienen registros de propiamente epidemias, las enfermedades antes citadas suelen ocurrir, afectando poblaciones vulnerables como son las personas que viven en estado de marginalidad, niños, ancianos o personas con enfermedades crónicas.

\section{Conclusiones}

El sitio estudiado se caracteriza por ser una microcuenca muy urbanizada que forma parte del proceso de Conurbación entre las ciudades de Heredia y Alajuela. En el sector, aproximadamente 190 viviendas no cuentan con alcantarillado sanitario o tanque séptico, distribuidas en 82 UGM, por lo tanto las aguas negras y residuales son dispuestas directamente a ríos, quebradas, zanjas o huecos provocando un impacto significativo en el ambiente.

La microcuenca baja presenta una cantidad considerable de eventos en el sector de San Antonio de Belén, sector que se caracteriza por presentar mayores áreas en la categoría de alta amenaza por inundación, lo anterior relacionado a la capacidad de permeabilidad que a venido perdiendo la cuenca por los desarrollos urbanísticos que se han desarrollado y que están por desarrollarse. 
Un punto sobresaliente es el predominio de residencias urbanas en la microcuenca, el 97,5\% de las viviendas se encuentra en esta zona. Casi un $87 \%$ de las viviendas del área de estudio corresponde con casas independientes.

En el sector de Los Ángeles hay un predominio del paisaje rural y con viviendas dispersas sobre las carreteras, mientras que en los distritos de Belén predominan usos de la tierra dedicados a industria, zonas francas, comercio y en menor residencial.

El ser humano ha ocupado estas áreas para desarrollar sus actividades socioeconómicas y se presentan desbordamientos como los presentados durante varios eventos, impactan con pérdidas económicas, sociales o ambientales, especialmente en espacios densamente poblados como en la microcuenca estudiada.

\section{Bibliografía}

DINADECO. 2015. Sistema Nacional de Registro de Asociaciones.

Instituto Nacional de Estadística y Censos (INEC). 2010. Manual para censistas. X Censo Nacional de Población y VI de Vivienda Costa Rica. Disponible en https://international.ipums.org/international/resources/enum_materials_pdf/enum_instruct _cr2011a.pdf.Consultado en mayo de 2016.

Instituto Nacional de Estadística y Censos (INEC). 2011. Censo Nacional de Población y VI Censo Nacional de Vivienda 2011. Base de datos cedida para el proyecto ED3226.

Laboratorio de Análisis Ambiental, Universidad Nacional y Programa Observatorio Ambiental, Municipalidad de Belén. 2012. Programa para mejorar la calidad de las aguas superficiales en cantón Belén 2012-2017. Disponible en https://www.belen.go.cr/images/PDF/desarrollo_ambiental/Calidad-

agua/programa\%20proagua\%20belen.pdf, Consultado en setiembre de 2016.

Marín, M. 1991. Estudio del escurrimiento y la contaminación en la cuenca de la Quebrada Seca. Tesis de Licenciatura. Escuela de Ingeniería Civil. Universidad de Costa Rica. San José. 
Masís Campos, Ramón; Vargas Picado, Huberth. 2011. Análisis de los cambios del uso de la tierra en 1960, 1990, 2010 y su efecto en el comportamiento hidrológico en la microcuenca del río Burío, Heredia, Costa Rica". Tesis de grado para optar por el título de Licenciatura en Geografía.Universidad de Costa Rica, Facultad de Ciencias Sociales, Escuela de Geografía.

Ministerio de Vivienda y Asentamientos Humanos (MIVAH). 2005. Ubicación y perfiles de los asentamientos en precario y en tugurio del Gran Área Metropolitana. Disponible http://www.mivah.go.cr/Documentos/precarios/Precario_Tugurio_GAM_Febrero_2005/In troduccion_Ubicacion_Perfiles.pdf. Consultado en mayo de 2016.

Municipalidad de Belén (2007). Desarrollo Ambiental. Descargado desde https://www.belen.go.cr/web/guest/desarrollo-ambiental

OpenStreetMap (OSM) (2016). Base de datos de OSM del área de estudio. Disponible en https://www.openstreetmap.org

PRUGAM. (2016) La cartografía de usos de la tierra a escala 1:10.000 para la Gran Área Metropolitana, en el marco del proyecto PRUGAM http://www.mivah.go.cr/PRUGAM.shtml,Consultado en mayo de 2016.

Sala Constitucional de la Corte Suprema de Justicia (2005). Sentencia 04050. Exp: 03001735-0007-CO. San José, Costa Rica.

Segura, Laura. 2004. Modelación hidráulica de la Quebrada Seca para el manejo de inundaciones en el Cantón de Belén. Tesis de Licenciatura. Escuela de Ingeniería Agrícola. Universidad de Costa Rica. San José. 
Sistema de Inventario de Efectos de Desastres (Desinventar). (2016). Base de datos Costa Rica - Inventario histórico de desastres 1968-07-29 - 2016-08-26. Disponible en https://online.desinventar.org/desinventar/\#CRI-1250694968-

costa_rica_inventario_historico_de_desastres. Consultado en mayo de 2016.

Sistema Nacional de Información Territorial (SNIT) (2016). Distritos, cantones, provincias, curvas de nivel y ríos a partir del servicio WFS. Disponible en http://www.snitcr.org/servicios/datos/wfs?,Consultado en mayo de 2016.

Vallette, C.(2009). Datos históricas sobre el rio Quebrada Seca en el cantón de BelénHeredia, 1777-1987. Comisión Especial del río Quebrada Seca. Belén. 